\title{
A Novel Visual Recognition-based Authentication Model Using a Hybrid Trust Theme to Verify Provider Profiles for Enhancing Information Assurance in Online Healthcare
}

\author{
Ankur Chattopadhyay, Michael J. Schulz*, Katie L. Turkiewicz \\ and Eli Hughes \\ Department of Information and Computing Sciences, \\ University of Wisconsin - Green Bay, Green Bay, USA \\ E-Mail: mschulz2@express-scripts.com \\ ${ }^{*}$ Corresponding Author
}

Received 19 April 2018; Accepted 23 April 2018;

Publication 19 June 2018

\begin{abstract}
As the number of online healthcare consumers grows day by day, we notice a corresponding rise in the quantity of online healthcare information $(\mathrm{OHI})$, as provided by a large number of different healthcare related web service providers, including several third-party websites, like HealthGrades.com, ZocDoc.com, and ShareCare.com. Given the convenience and ease of having $\mathrm{OHI}$ at their disposal through web browsing, today's healthcare often resort to making "Dr. Google" their first point of contact instead of an actual physician. However, this may lead to cyber psychological issues, like cyberchondria, which are related to uncertainty, mental anxiety, and credibility concerns in regard to OHI. Existing literature shows that there been some research work done on the challenges posed by cyberchondria like cyber psychological issues, especially in non-computing disciplines. However, to our knowledge, the research work, as presented here, is the first of its kind to directly propose
\end{abstract}

Journal of Cyber Security and Mobility, Vol. 73, 1-46. River Publishers doi: $10.13052 / \mathrm{jcsm} 2245-1439.733$

This is an Open Access publication. (c) 2018 the Author(s). All rights reserved. 


\section{A. Chattopadhyay et al.}

an information assurance driven technical computing solution to this interdisciplinary problem. None of the previous research work has proposed to address the reliability issues associated with $\mathrm{OHI}$ by handling multi-layered trust antecedents from different domains at both the website and the organizational levels. Additionally, the OHI research in these efforts have not cumulatively accounted for multi-level factors like security, assurance, social presence, verification, reputation, and familiarity, which together contribute towards building trust for countering cyberchondria. Hence, in order to enhance the process of trust formation for $\mathrm{OHI}$, we conceptualize and propose a novel hybrid is driven by biometric authentication of physician image profiles. Our proposed approach uniquely addresses the multi-dimensional and social aspects of $\mathrm{OHI}$ related trust building, including interpersonal equations of both the patient and the physician at the website as well as the institutional levels. One of the major contributions of this work is proposition of a hybrid, multilayered analysis model for OHI based trust computing that includes a unique, improvised amalgamation of different trust factors from interdisciplinary and disciplinary research domains, including information assurance and security. The uniqueness of this model lies in its biometrics-inspired basis, along with its hybrid trust focus with a fine blend of soft trust and hard trust approaches. As part of our research investigation with this proposed approach, an experiment has been conducted with a unique set of about close to seventy (70) OHI website based physician visual profiles in order to demonstrate a potential implementation of this trust-computing model. Another significant contribution of this research is the creation of the first of its kind unique dataset of acceptable physician profile images from various $\mathrm{OHI}$ websites in relation to testing our proposed OHI trust-computing model based approach. We see this research work as a novel initiative for improving OHI credibility in an effort to set up a prospective benchmark pathway towards a new multi-dimensional $\mathrm{OHI}$ trust metric for addressing cyberchondria like cyber psychological issues. The entire collection of our varied experimental results from this research are shared and reported as part of this paper. We believe that this work will drive further innovative research experiments with the novel OHI trust computing model, as proposed in this paper, and shall form the basis of future trust computing research towards finding ways to mitigate cyber psychological issues in the realm of $\mathrm{OHI}$.

Keywords: Antecedents, Authentication, Biometric, Consumer, Cyberchondria, Hard Trust, Hybrid Trust, Online Healthcare Information, Provider, Soft Trust, Visual Recognition and Verification. 


\section{Introduction}

The Internet profoundly impacts the way people search for, utilize, and communicate about healthcare information. According to a nationwide survey on Internet use, eight out of ten American adults search online for healthcare information [1]. More specifically, 83\% of those surveyed indicated using the Internet to look up a particular disease or medical problem [11]. In short, there is a tremendous amount of online health information (OHI) available to the typical consumer and there are no standard mechanisms and regulations, including credibility standards for $\mathrm{OHI}$, that embodies or characterizes how to make 'trust' decisions as online healthcare consumers [37]. Although active OHI users make such 'trust' judgments all the time, there is no method or approach to comply with the rationale of making such decisions [40].

The topic of online information trust is a particularly important issue in the context of health information acquisition. While record numbers of U.S. adults are turning to the Internet to self-diagnose, seek treatment options and choose a physician, many people encounter a number of challenges. The inability to find accurate information [2], inconsistent advice or information [10, 24], the inability to make sense of health information [3] and the psychological distress resulting from the information seeking process [4] are all examples of some of these challenges. For example, cyberchondria is the experience of heightened anxiety related to medical disorders resulting from OHI seeking [5]. Research in this field suggests that some people are particularly vulnerable to bouts of distress related to online information seeking. Individuals with high health anxiety seek $\mathrm{OHI}$ more frequently and spend longer searching online. Individuals with high health anxiety find searching for health information online more distressing and anxiety provoking. At the same time, levels of health anxiety are positively related to the frequency and the duration of OHI searches [6]. This cyclical pattern of distress in information seeking have detrimental effects on the individual, who is generally already suffering from an acute or chronic health condition that prompted the initial search.

The notion of trust can be attributed to a multi-dimensional, multidisciplinary concept with a complex interpersonal connotation and social context [11, 12, 14, 20, 23, 37]. However, the OHI seeking and cyberchondriarelated trust issues have never been researched from the perspective of soft trust and hard trust components [40] as applicable in computing disciplines $[27,34]$. One important component of trust has to do with user rejection or selection of a particular site. It stands to reason that consumers will engage with sites they view as trustworthy and reject those they mistrust $[10,24]$. 
Research in the area of OHI trusts suggest mistrust of websites is based on design factors, including the use of images [3] while trust of websites is based on content factors such as source credibility and personalization [10, 24]. For example, [21] argues that consumers tend to trust sites with visual appeal and mistrust those with poor visual design. Thus, images as part of the design or visual appeal can play a guiding role in user trust of OHI. This heightened trust has the potential to decrease anxiety associated with the information acquisition process.

A number of studies have noted a link between the use of images and user trust of health websites. These studies suggest that images increase trust by creating a sense of familiarity or endorsement. Consumers appear to be influenced by the branding of the site or by the presence of familiar images or trusted logos [10, 21, 24]. For example, [2] found that online design factors such as visual appeal, first impression, images and video messages on the web attracted elderly adults seeking OHI, thereby creating a personal connection between the user and the content. Existing literature [10, 19, 21, 22, 24, 36] argue that trust in $\mathrm{OHI}$ can be influenced by trust inducing attributes like website endorsements, scientific imagery and prominent features, such as photographs. They suggest that the quality of information available on a website plays a role along with the perceived profile plus expertise of the providers (or the physicians). They also reason that $\mathrm{OHI}$ trust is driven by the extent to which the provider appears to be familiar and connectable through a shared social identity.

\subsection{The Cyberchondria Connection: Issues and Challenges}

Cyberchondria has been considered as a distinct mental disorder and a multidimensional concept with mistrust of medical professionals as one of its key features [7]. Cyberchondria is not simply hypochondriacs using the Internet, but rather a distinct form of online information seeking and resulting escalating health anxiety. Recent research has found that cyberchondria is actually more closely aligned with other forms of problematic Internet use (i.e., compulsive online shopping, online gambling, and online pornography consumption) than traditional hypochondria [4].

More specifically, behavioral manifestations of hypochondria and cyberchondria are where the key differences between the two become apparent. Cyberchondria involves a cerebral response to a lack of information. Conversely, hypochondriacs convince themselves they are suffering from a specific medical condition, manifest physical reactions to their perceived 
symptoms, and engage in behaviors that enact their concerns (i.e., going to see a doctor). Therefore, the enactment of cyberchondria is far less physical and disruptive, as it centers on increased cerebral efforts to gather information. The primary impetus for hypochondria is the conviction that one has a specific medical condition, whereas cyberchondria is primarily driven by a desire to acquire more information about a specific condition. Furthermore, cyberchondria is less likely to evolve into behavioral responses and more likely to be sustained at the cerebral level. The lower levels of physical commitment make cyberchondria more diffuse and manageable than hypochondria.

Cyberchondria has been a social phenomenon that has evolved along with the increase in Internet use for obtaining $\mathrm{OHI}$ and the rise in online healthcare consumerism [5]. One of the ways people are employing the Internet for their health care needs is as a diagnostic tool [9]. People input various search engine queries related to symptoms they may be experiencing or are interested in understanding better and view the search results as carrying some authority. This is also sometimes pejoratively referred to as "asking Dr. Google."

The social implications of cyberchondria are substantial, but for the sake of brevity, this discussion will expand on the larger issues of credibility. Any form of problematic or compulsive use of the Internet has social impact [7]. What makes cyberchondria a unique challenge is the component of personal health. A person's physical well-being is never to be taken lightly and the ubiquity of erroneous or misleading health information on the Internet is a very real issue. This leaves the OHI seeker with the sole responsibility of wading through all the available information to determine what is credible. Consequently, there are individuals routinely seeking out health information online only to be misled or misinformed. The primary concern is a distorted or inaccurate perception of personal risk due to online misinformation and deception. The potentially erroneous information, which people find while online, can lead to unfounded anxiety [6]. Furthermore, the hope that the quality of OHI will improve over time is unlikely. There are reputable and credible sources of health information online, but $\mathrm{OHI}$ is not regulated and should never take the place of a health care provider's examination, treatment, or advice.

The increasing availability of health information online (whether credible or not) is not the only contributing force behind cyberchondria [9]. Another factor to be considered is the health care consumerism movement. Modern consumer culture has generated attitudes toward health care as a lifestyle choice that is personally managed and maintained. Taking an increased interest 


\section{A. Chattopadhyay et al.}

in personal health decisions is not inherently problematic, but generally considered proactive and admirable. Furthermore, people interested and involved with their own healthcare are more likely to improve their health circumstances. An unfortunate and extreme response to the health care consumerism movement has resulted in some people selectively ignoring or avoiding professional medical care and using the Internet as a major information source for their health care needs. This is leading them to information without medical guidance and supervision.

Potentially dubious $\mathrm{OHI}$ and health care consumerism are social impact issues contributing to cyberchondria that generally fall under individual control. The effect cyberchondria can have on the relationship and communication of a patient and a health care provider broadens the impact more directly to social interactions and relationships. The impact of cyberchondria on the health care provider-patient relationship has been previously examined $[5,6]$. The overall assessments vary from marginally positive (i.e., a patient's improved access to OHI supports patient empowerment and an improved partnership with the health care provider in proactively managing personal health) to very negative (i.e., health care providers resent being questioned by their patients about healthcare decisions, feel the Internet promotes 'doctor shopping,' and sometimes take punitive measures with Internet-informed patients who question their authority). For better or worse, the availability of $\mathrm{OHI}$ and how people chose to consume it is fundamentally changing how patients interact with their health care providers.

The avenues of potential research into the phenomenon of cyberchondria are vast. As a form of problematic Internet use, cyberchondria can be readily examined from the perspective of technology and its impact on social change [4]. As previously discussed, the health care provider-patient communication dynamic has already been established as a dyad significantly influenced by the availability of OHI. It is important to clarify that simply going on the Internet to research a health-related topic does not make someone a cyberchondriac. Similarly, a diagnosed hypochondriac who uses the Internet to seek out health information does not become a cyberchondriac rather than a hypochondriac.

Overall, cyberchondria has evolved from a number of factors including increased Internet availability, increased Internet access, health care consumerism, and the costly health care system [7]. The current issues of vast amounts of dubious health information on the Internet, increasing demands on the healthcare system, the overall decline in national health, the increasing elderly population, and the steady rise in diagnosed chronic medical conditions 
ensure that the role of technology in healthcare will only expand. As people increasingly turn to technology for answers and assistance, it is vital that medical professionals and researchers fully understand the limitless potential it can have to both supplement and undermine an individual's ability to personally manage their own health.

Non-technical social science research disciplines (like communication, psychology) can contribute in a meaningful way to understand how cyberchondria affects society. However, it needs to collaborate with computing disciplines for providing actual tangible solutions. This is where finding innovative technical application tool-based solutions for determining the credibility of $\mathrm{OHI}$ becomes essential. This paper builds the foundation for future interdisciplinary research on providing technical models to determine an "antidote" to cyberchondria like cyberphychological issues. The model implementation of our unique biometric authentication based OHI trust model, as proposed in this paper, represents the start of a much larger project anchored in $\mathrm{OHI}$ trust assessment. Automating the examination of healthcare provider profiles for biometric trust markers and accuracy leads to building an innovative software tool with the potential to evaluate $\mathrm{OHI}$ by computing trust value. This would provide users with an improved trustworthy perception of $\mathrm{OHI}$, thereby mitigating the effects of cyberchondria.

\subsection{Importance and Motivation of Research}

Trust can be a mediating factor for addressing the challenges associated with $\mathrm{OHI}$ seeking and for countering cyberchondria, as discussed in the previous sections. Recent papers like [9] directly argue that the effects of cyberchondria can be minimized if online healthcare consumers can find an easy way of determining the trustworthiness of an $\mathrm{OHI}$ website. The research presented in this paper is firstly motivated by the need of persuasive imagery in building trust in OHI, as cited in the earlier section. This forms the basis of using visual profiles at the provider level for the trust-computing model proposed in this paper.

Secondly, what inspires this research is the requirement of establishing trustworthiness in OHI, as part of information assurance, which the proposed research handles innovatively through biometric authentication. Recent literature [10, 14, 21, 37] emphasizes the development of trust in OHI through systematic evaluation of content, concluding that consumers are more likely to trust $\mathrm{OHI}$ if they could verify the available information by crosschecking it with other websites through integration of information across multiple sources and different sites. Even though few publications [12, 15, 37] discuss 
credibility and acceptability as contributing factors towards trustworthiness of online information, they do not actually illustrate or demonstrate how the process of authentication can be employed to serve the cause. In this aspect, this paper is the first of its kind to apply computer vision [27], in the form of visual recognition based biometric authentication, towards the field of $\mathrm{OHI}$ to innovate data evaluation via cross-verification.

It should be noted herein that there has been some ongoing research $[31,32]$ in ubiquitous, connected healthcare, using sensors and cloud computing for enhancing trust computing. These efforts have made use of sophisticated models of user authentication, including user reputation based profiles, and role based access control systems for improving healthcare. However, this paper focuses on a problem within the sphere of online healthcare consumerism associated with the issue of cyberchondria, which is a different and stand apart case. There has also been some recent trust, authentication and reputation based research $[13,15,16]$ on web content in relation to e-commerce and social media platforms like Twitter, Facebook, etc. These efforts have looked into the user trust, confidence and credibility levels using social profiles through techniques like machine learning based classification and analysis by cross-validation based authentication and verification via trusted sources. However, none of the OHI research has directly used visual recognition based machine learning for addressing trust and reputation through a biometric authentication and verification process.

Additionally, the previous trust computing models in OHI [12, 19, 37] have employed user-centric models for evaluating trust. These models have only been limited to covering trust constructs at the consumer and website levels [18, 20]. Existing literature [11, 14, 33] argue that trust is a multi-dimensional entity and needs to be expanded to a broader context by considering trust inducing factors at the institutional level. Most $\mathrm{OHI}$ trust related research $[23,25,26]$ has traditionally accounted for only trustor-focused attributes. They have typically undermined or neglected the organizational trust antecedents like expert (or provider) profile, reputation, verification, familiarity and social identity $[18,20]$. Some researchers clearly make the point how perceived credentials of involved experts in OHI can make an impact on building trust in OHI [14, 21, 22]. Thus, in order to fill in these mentioned gaps in $\mathrm{OHI}$ trust related research practice, this paper proposes a new provider-centric $\mathrm{OHI}$ trust computing model, which extends the determination of trustworthiness to the trustee level by validating institutional trust components like provider perception, reputation, verification, acquaintance and social connect through biometric authentication unlike other trust models. 
Lastly, the OHI trust related research described in this paper analyzes the trust computing model from the perspective of soft trust and hard trust [27, 34], and this has never been done before. Therefore, this paper strives towards conducting a soft trust and a hard trust based analysis [40] within the OHI realm for the very first time. The novelty of this paper lies in the hybrid trust approach [35] that is proposed here for improving the trust-based decision making of OHI seekers. Thereby, this research effort is to help take a positive step towards mitigating cyberchondria.

As mobile technology continues to seamlessly integrate into the modern lifestyle and the national healthcare system continues to be intractable, it is imperative to have an effective and reliable resource, in the form of a trust computing model, for determining the credibility, authenticity and acceptability of OHI. The current research, as presented here, seeks to address the above demands of the OHI trust domain and enhance the contemporary state of the visual design of related websites. Overall, this paper introduces a fresh provider-centric $\mathrm{OHI}$ trust-computing model, that is driven by biometric authentication. Additionally, the research conducted in this paper explores the role of trust in $\mathrm{OHI}$ acquisition from a unique hybrid standpoint, and proposes a technical solution to reduce the potential anxiety associated with the process of seeking accurate and relevant OHI. This proposed solution paves the way for the creation of a tool to determine the credibility, authenticity and trust of OHI.

\section{Trust and Trust Antecedents}

In order to understand when trust can occur in a system, it is necessary to discuss the factors that a party bases their trust judgements upon in a given situation, known as trust antecedents [18].

In a systematic literature review of trust antecedents in an online context, perceived ease of use of the website, information quality, graphical characteristics, social presence cues, customization and personalization capacity, third party guarantees, and finally privacy assurances and security features were found to be website trust antecedents [36]. Additionally, organizational reputation, perceived size of the organization, offline presence and experience and familiarity with the company were found to be organizational trust antecedents (Figure 1).

"Perceived ease of use of the website" represents how simple or easy to use a website seems to be to a person and could include organization, navigation and searching tools on the site. "Information quality" is the relevancy, accuracy, completeness, depth, usefulness, or variety of the information on 
10 A. Chattopadhyay et al.

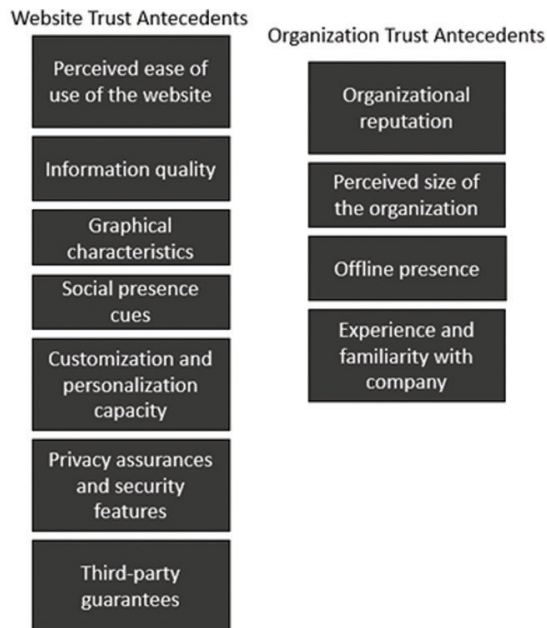

Figure 1 Website and organizational trust antecedents found through a literature review [36].

the site in question. "Graphical characteristics" are colors and art used in the site design. "Social presence cues" refers to elements of interactions on websites that increase the feeling of "social presence" in users. Social presence is the feeling of being connected through the online medium. "Customizaion and personalization capacity" refers to the options available on the website to change its features either to personalize it in response to information received from the user or as a response to customization from the user. "Privacy assurances and security features" includes privacy policies (even if they are not read) and security features for transactions. "Third party guarantees" could include items such as seals of approval, certifications, or other recognitions from a third party. These assurances can be categorized as relating to technology, privacy, or process. "Organizational reputation" is the perception of an organization's trustworthiness based on reviews or referrals, as well as a perception of the credibility of the organization to follow through on promises. "Percieved size of the organization" may or may not be an important factor in forming trust on the part of a consumer who is shopping online, possibly shaped by the item they intend to purchase. "Offline presence" refers to previous experience consumers may have had with the physical realworld organization and how that may influence their willingness to trust the online representation of the same organization. "Experience and familiarity with the online company" refers to the experiences users have had with a website where they previously tested its trustworthiness or were satisified [36]. 
A literature review focused on $\mathrm{OHI}$ found information quality, ease of use, appearance, and system quality to be website trust antecedents, while perceived reputation, perceived risk, familiarity and prior experience with using health information websites were found to be consumer-website interaction trust antecedents (Figure 2) [18].

"Information quality" is the relevance, consistency, completeness, timeliness or accuracy of information. "Ease of use" is identified as a particularly relevant antecedent related to both trust and indirect trust through credibility. "Appearance" was found to impact trust, including items such as layouts, advertisements and menus. While some studies surveyed found no association between trust and appearance, another had a subject comment that they wanted to see a face before they could determine trustworthiness. "System quality" refers to elements of the user interface such as adaptability, usability, and flexibility. "Perceived reputation" refers to how reputable an organization is perceived to be by the website user. For example, insurance company websites were not perceived to be trustworthy, while government websites were. "Perceived risk" is the perception of the potential for experiencing a loss. "Familiarity" is rooted in previous interactions with other parties by the user. "Prior experience using health information websites" may have a positive or negative impact on trust, possibly depending on the nature of the previous experiences of the user [18].

In an investigation into the effects of design on online trust, Sillence and Briggs found that navigation design and visual appeal are both possible

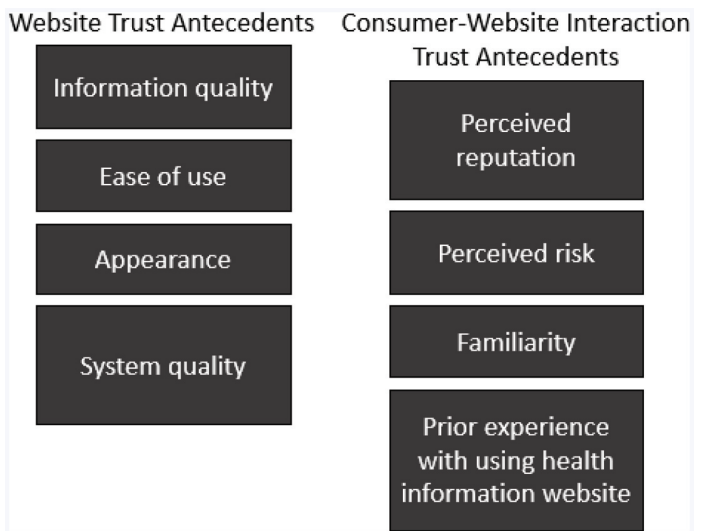

Figure 2 Website and consumer-website interaction trust antecedents found through a literature review of trust antecedents in online health [18]. 


\section{A. Chattopadhyay et al.}

trust antecedents for websites (Figure 3) [24]. Other design elements such as personalization and social networking were related to longer-term trust relationships between the consumer and the website.

Existing research on online trust information quality has listed the ease of use, graphics, customization, privacy and security, third party guarantees, and social presence were listed as website trust antecedents. Reputation, offline presence and famliairity were determined to be organization based trust antecedents (Figure 4) [42].

Definitions of the trust antecedents listed above generally followed the corresponding definitions from the previously mentioned literature reviews $[36,18]$. However, it is noted that "third party guarantees" is focused on e-commerce specifically.

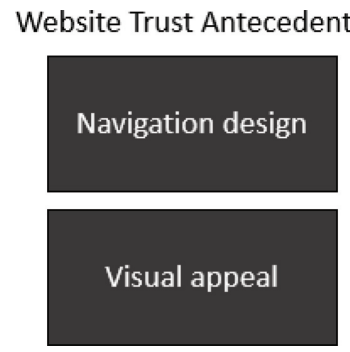

Figure 3 Design elements of websites that could act as trust antecedents [24].

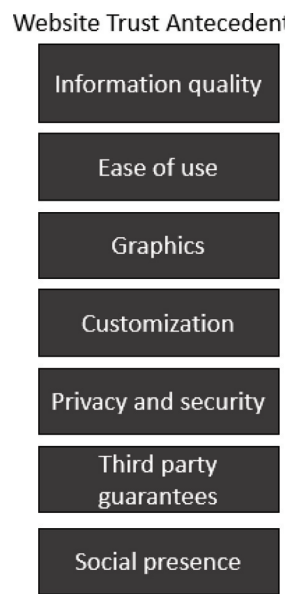

Figure 4 Trust antecedents as defined by a paper investigating how trust has been researched in an online context [42]. 


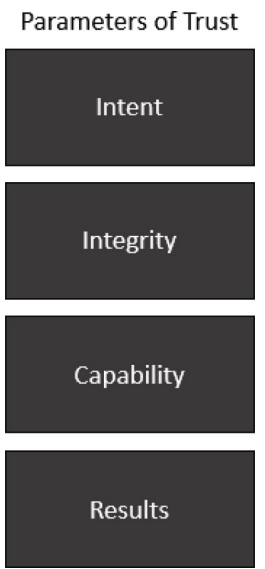

Figure 5 Parameters of trust that could act as trust antecedents [41].

Additionally, intent, integrity, capability and results are elements of trust models based on human behavior (Figure 5) [41]. We have also considered these as potential antecedents of trust.

"Intent" refers to the trustee's state of mind of willingness to commit a certain action. "Integrity" is consistently delivering what is expected to trustees. "Capability" is made up of every resource needed to deliver what is expected. Finally, "results" are focused on outcomes of the interaction.

\section{Integrating Soft Trust With Hard Trust}

There are several OHI websites that contain healthcare service provider related details. The driving question that the typical OHI seeker is routinely faced with [9], is which source to trust? With only the webpage content as the means for assessing trustworthiness and credibility, the importance of that content for user trust assessments is substantial. To illustrate this issue, a few different OHI websites are examined and explained. The first one, ABIM (American Board of Internal Medicines).org [30], is a well-known and medically accredited website with board certifications and professional endorsements. This website provides board certification information for the healthcare providers it features. Board certified credentials are an example of hard trust features [25, 40]. In addition to the board certifications, ABIM.org features physician photographic profiles that can act as visual biometric indicators that can be computed through cross-reference with other photo 


\section{A. Chattopadhyay et al.}

profiles from different online sources for verification purposes. The use of hard trust features, including biometric attributes, on ABIM.org, sets up an opportunity for comparison to other non-accredited $\mathrm{OHI}$ websites dominated by soft trust elements.

HealthGrades.com [29] and ZocDoc.com [28] are both examples of websites intended for healthcare consumers seeking OHI. These sites contain data on healthcare service providers as well as reviews on physicians authored by patients. This content plays a role in formation of consumer opinions leading to user beliefs. The healthcare consumers have to determine on their own if they will trust the authenticity and accuracy of the user "review" data available on these websites. The contents of such OHI websites can be useful and may be regarded as valuable by public consumers, but they lack validation due to the possibility that they have been manipulated or even fabricated. If a trust decision is made on the basis of the soft user content of such websites, then that would lead to a case of soft trust building without hard trust assessment.

Figures 6 and 7 display preview profiles of the same physician, Brian Stanley Smith, including headshot photos in ABIM.org and HealthGrades.com, respectively. Similarly, Figure 8 shows the online screenshot of the visual profile of another physician, William Montesano on ZocDoc.com. According to the biometric trust-computing model, as proposed in this paper, the physician profiles on these two websites can be validated against one another using biometrics on the visual content. In other words, the healthcare service

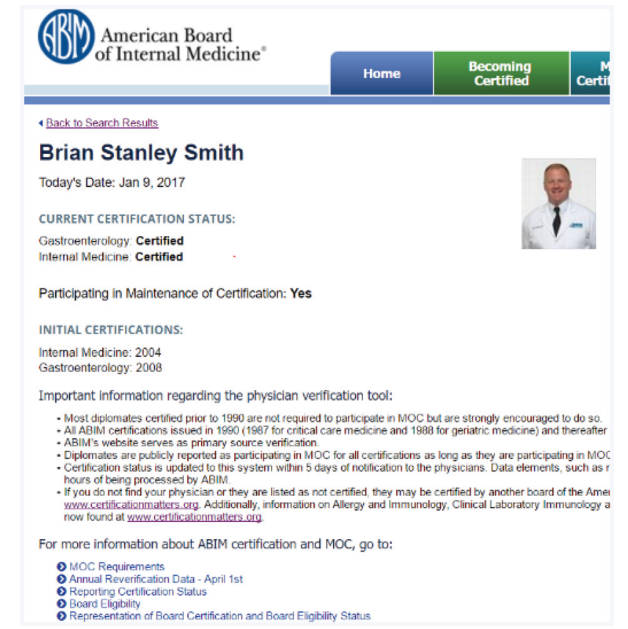

Figure 6 ABIM.org Profile of Brian Stanley Smith, MD. [30]. 


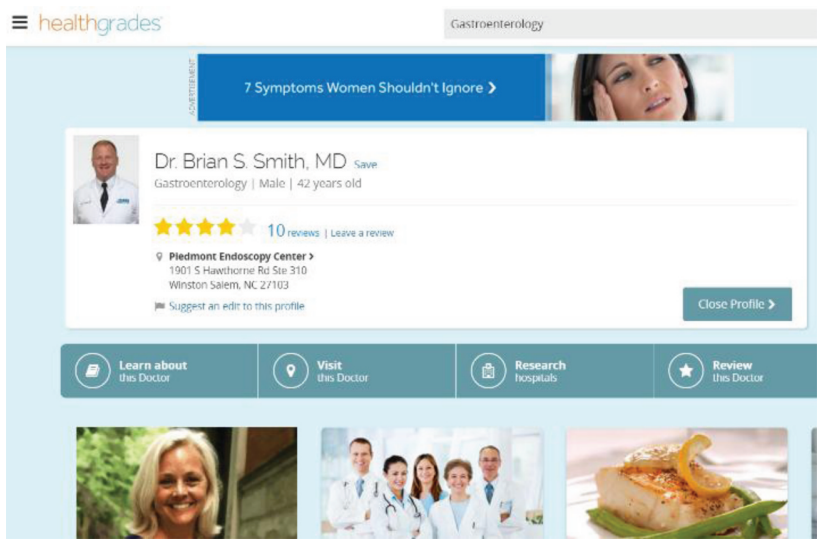

Figure 7 HealthGrades.com Profile of Brian Stanley Smith, MD. [29].

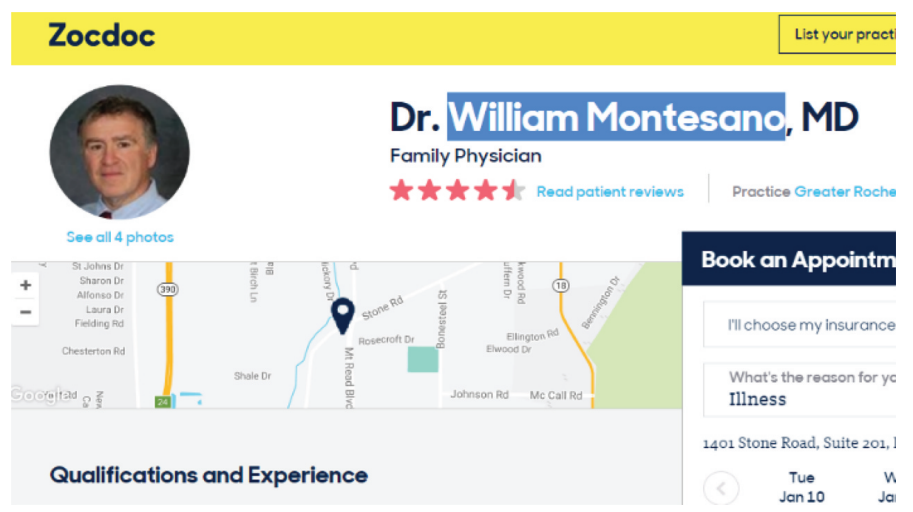

Figure 8 ZocDoc.com Profile of William J. Montesano, MD. [28].

provider based soft content hosted on common healthcare consumer-focused websites (like HealthGrades.com and ZocDoc.com) can be examined using corresponding physician profile data from medically accredited websites (like ABIM.org or the official healthcare provider website resources) using vision computing based biometric authentication.

This technical process of provider-centric cross validation using biometrics lays the foundation for a hard-trust computing mechanism using soft data and creates a hybrid trust paradigm, the first of its kind in validating OHI. This hybrid trust model is intended for developing more confidence and added credibility among OHI users. It is also meant to provide more peace of mind to users for important trust decisions, and counter cyberchondria 
in the process through verification of OHI trustworthiness via biometric authentication. Combining hard and soft trust elements in the described hybrid approach to determine trustworthiness is a more comprehensive and effective indicator of credibility in OHI. This is because the proposed model, unlike other existing models, elegantly handles and validates the institutional trust antecedents beyond the usual scope of the consumer and website.

\section{Visual Recognition Biometrics to Improve Trust}

The use of biometrics in conjunction with computer vision [27] has demonstrated robust authentication processes in the field of security, consequently earning the trust and assurance of users. Successful instances of biometrics include fingerprint scanning, retina identification, and voice recognition implemented in advanced technological applications and trusted secure facilities. However, existing literature on $\mathrm{OHI}$ and cyberchondria suggest that neither biometrics nor vision computing has been meaningfully applied to benefit and enhance the trust values of online healthcare consumers. There is a large number of non-recognized healthcare websites available online that lack any sort of official certification or endorsement. Yet, they publish a lot of detailed information on healthcare service providers as well as physician profiles, including photographic images in some instances. This raises a common trust issue for OHI users and poses the question as to how to validate these non-accredited online profiles.

\subsection{Proposed Biometric Trust Computing Model}

The proposed biometric OHI trust-building approach is modelled using a visual recognition based computing paradigm, as depicted in Figure 9. In order to implement a proof-of-concept application of our model for conducting a research experiment, IBM Watson's visual recognition platform [8] is chosen as a biometric computing platform for evaluating trust in OHI. As illustrated in Figure 9, the visual recognition application sets up an image classifier file using images acquired from accredited medical databases. The classifier is then used to analyze images acquired from the OHI websites and returns a matching score for each image. All biometric scores are subsequently recorded and tallied to provide an overall provider-centric trust indicator. 


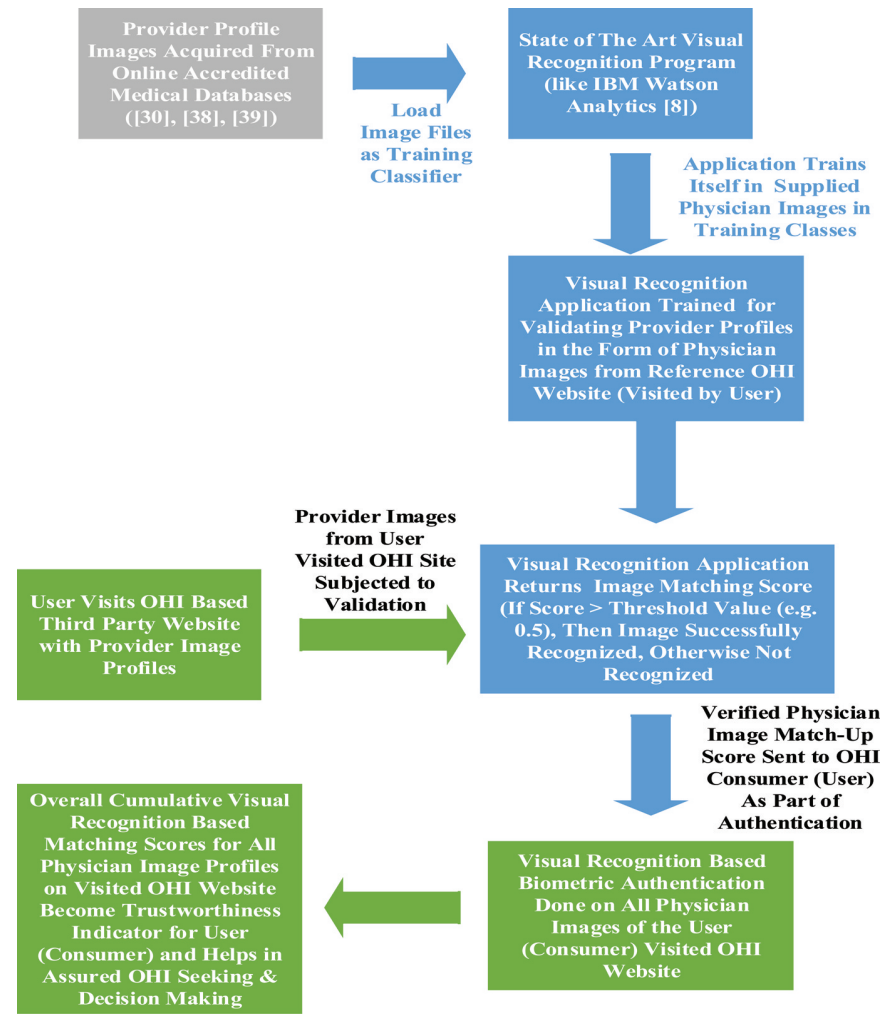

Figure 9 Block Diagram Representing Visual Recognition Driven Biometric Trust Computing Model for Enhancing OHI Trustworthiness.

\subsection{Image Sources for Biometric Trust Computing Experiment}

Various physician image profiles were chosen from several different OHI websites and a recognized provider network for implementing the proposed biometric authentication model as part of the conducted research experiment. These images contributed towards the construction of the distinct image classes needed for the experiment. A mixture of both medically accredited sites and social database sites were used in order to conduct the intended research experiment. HealthGrades.com [29], American Board of Internal Medicine (ABIM.org) [30] and ZocDoc.com [28] were utilized to pick images for the facial recognition test as well as corresponding training associated with the image classifier. Physician images from the Aspirus online medical staff directory [38] were chosen as the primary reference for the biometric 
validation experiment along with Greater Rochester Internal Medicine [39] and ABIM.org.

\subsection{Training IBM Watson for Visual Recognition}

Upon acquiring the experimental physician image profiles from the selected OHI websites, these were placed into a compressed file and submitted to IBM's Watson Developer Cloud node.js interface [8]. Images from Aspirus [38], ABIM [30], and Greater Rochester Internal Medicine [39] were divided into two different classes, each named General Practitioner and Internal Medicine corresponding to each category of physician listed on the chosen sites. This experimental set up was intended to illustrate that the biometric classification can be driven not only by facial recognition, but also by the physician's area of medical expertise as an added matching attribute. The overall algorithmic process of IBM Watson's visual recognition analytics is depicted in Figure 10.

\subsection{IBM Watson Visual Recognition Experimental Results}

An important contribution of this work is the creation of the first of its kind unique dataset of acceptable physician profile images [82] from various $\mathrm{OHI}$ websites in relation to testing our proposed $\mathrm{OHI}$ trust-computing model

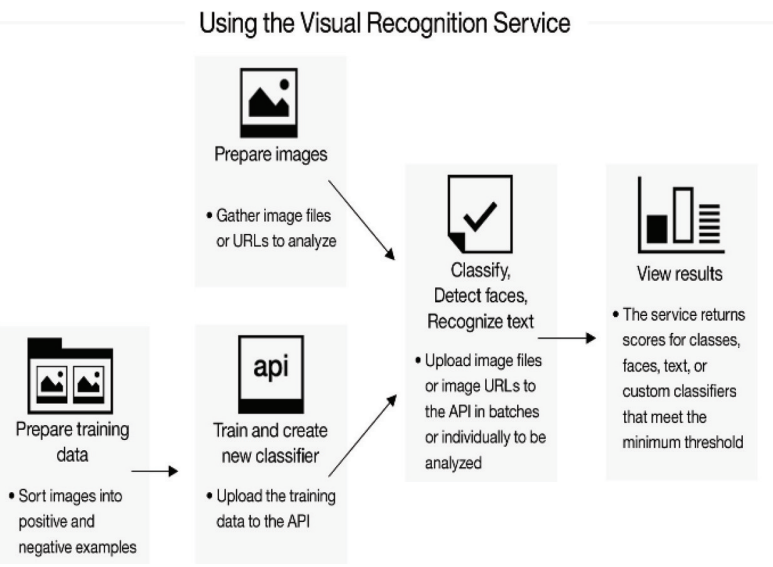

Figure 10 Block Diagram Representing the Algorithmic Process Used by the Visual Recognition Based Analytics Service of IBM Watson [8]. 
based approach. We have conducted several instances of research experiments based on the above mentioned dataset of OHI driven web physician profiles, which have been carefully selected and tested based on the acceptable criteria (like image size, resolution, quality, etc.) related the visual recognition based matching process of the physican images. Upon running the trained classifier images from the above mentioned sample dataset of almost seventy (70) physician visual profiles, most of the images were recognized above IBM Watson's accepted threshold score of 0.5 for visual recognition [8]. The first set of images were obtained from HealthGrades.com [29] and crosschecked against the Aspirus database [38]. The highest score result of the entire experiment was obtained from this set of data and achieved a score of 0.66 as shown in Figure 21. As per our observations, there were significant differences in image quality between physician photo profiles taken from the Aspirus database and the HealthGrades website, as well as intra-class quality variations between physician images within the same classifier category.

It is to be noted that as a major part of the conducted experiments (as exhibited in Figures 11 to 23), the Aspirus physician profiles were used for validating the HealthGrades.com images. Another part of the practical experiment was conducted by biometrically authenticating physician photographic images taken from ZocDoc.com [28] using the photo profiles from Greater Rochester Internal Medicine [39]. This test was found to be successful in spite of differences in the physician's attire, picture background, facial expression and age, as indicated in Figures 24 to 33. The IBM Watson visual recognition analytics tool [8] was able to overcome the above-mentioned hurdles and achieve decent match scores. The biometric validation for a HealthGrades physician image profile against the corresponding ABIM.org [30] profile returned acceptable matching scores via IBM Watson analytics, as shown in Figures 11 to 23.

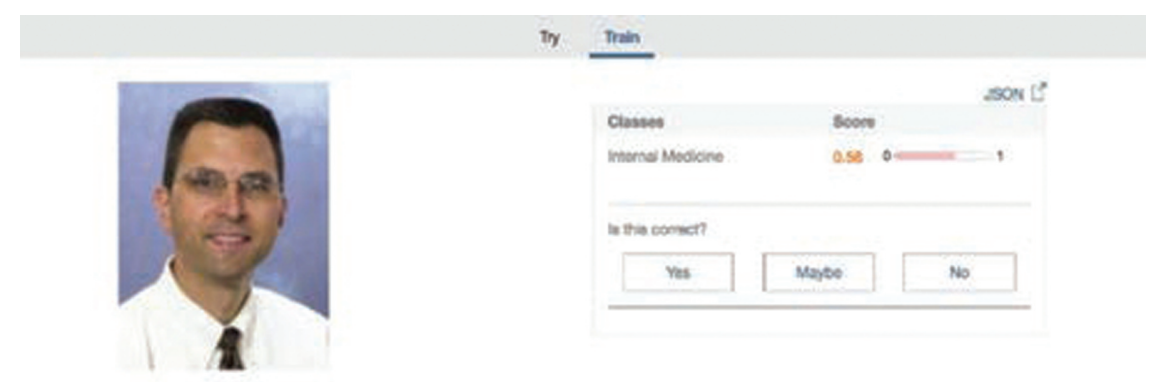

Figure 11 Image Profile Matching Score for Erik Anderson, MD. 
20 A. Chattopadhyay et al.

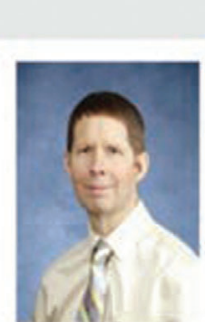

$\operatorname{Ty}$

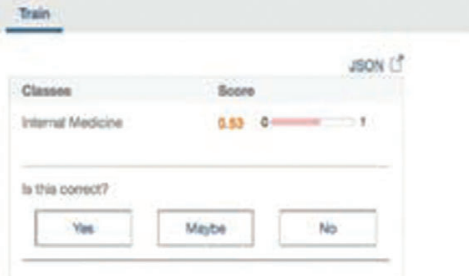

Figure 12 Image Profile Matching Score for Regis Chamberlain, MD.

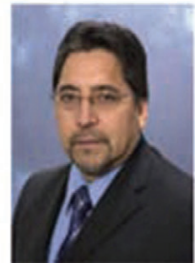

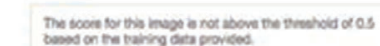

whas corsect

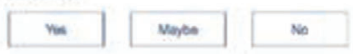

Figure 13 Image Profile Matching Score for Alberto H. Araya, MD.
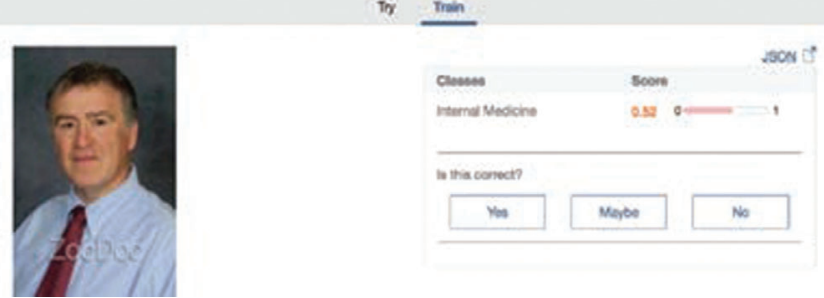

Figure 14 Image Profile Matching Score for William J. Montesano, MD.

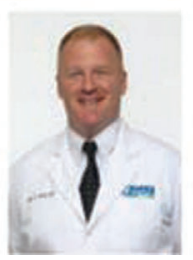

To

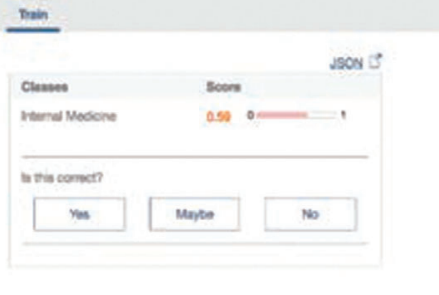

Figure 15 Image Profile Matching Score for Brian S. Smith, MD. 

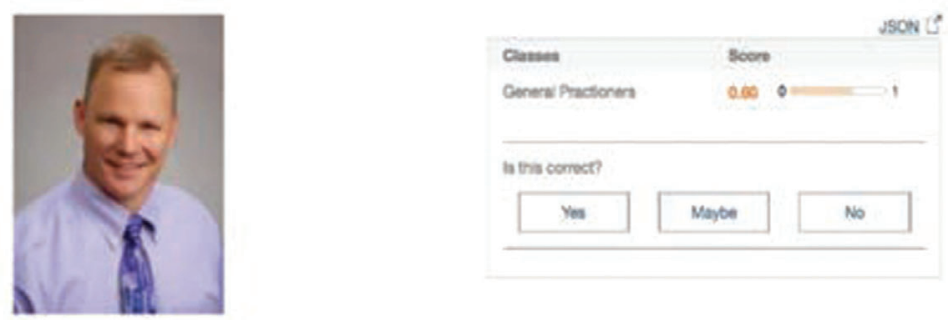

Figure 16 Image Profile Matching Score for Douglas P. Galuk, MD.
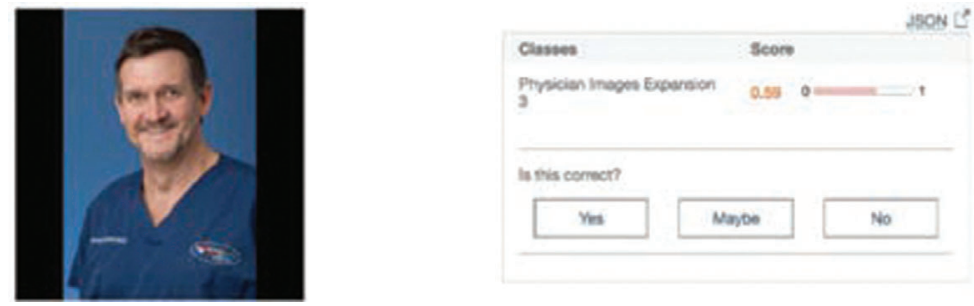

Figure 17 Image Profile Matching Score for Larry Crisco, MD.
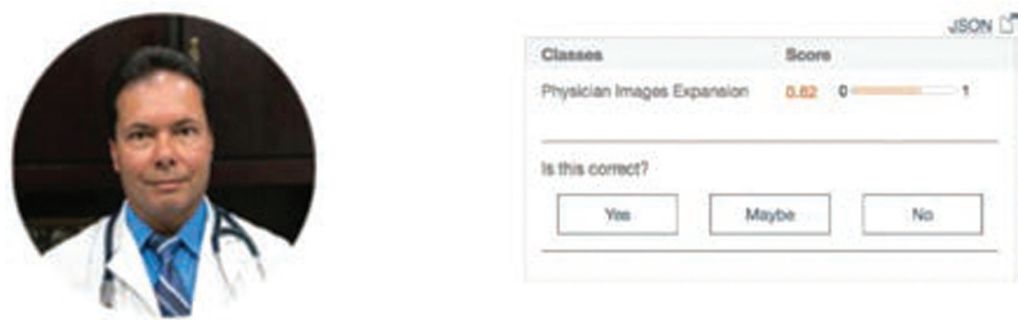

Figure 18 Image Profile Matching Score for Alberto Manzor, MD.
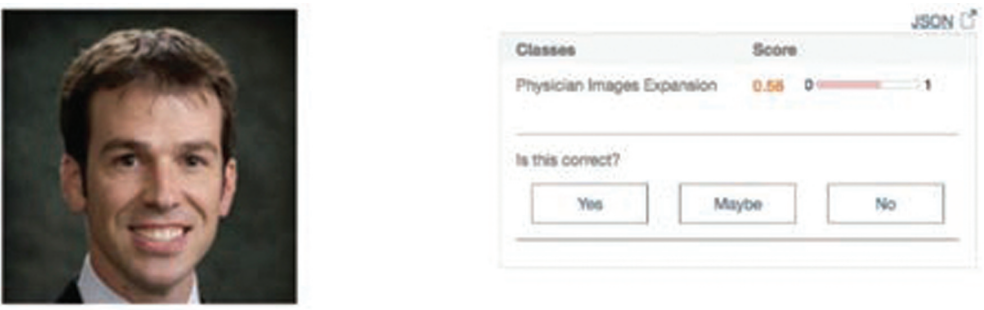

Figure 19 Image Profile Matching Score for Christoper Maxwell, MD. 
22 A. Chattopadhyay et al.
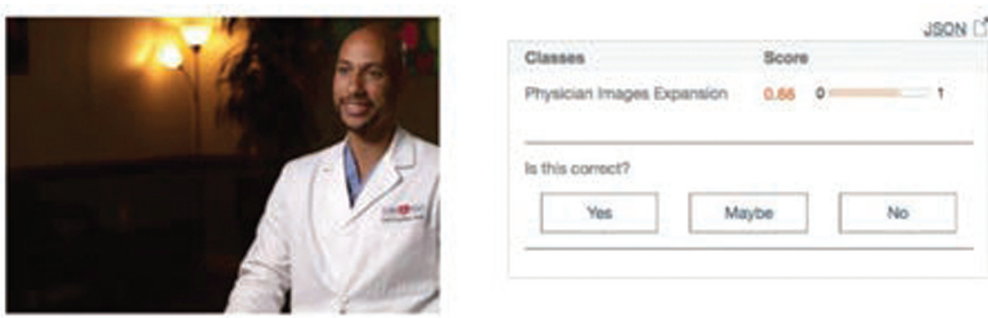

Figure 20 Image Profile Matching Score for Christopher Maxwell, MD.
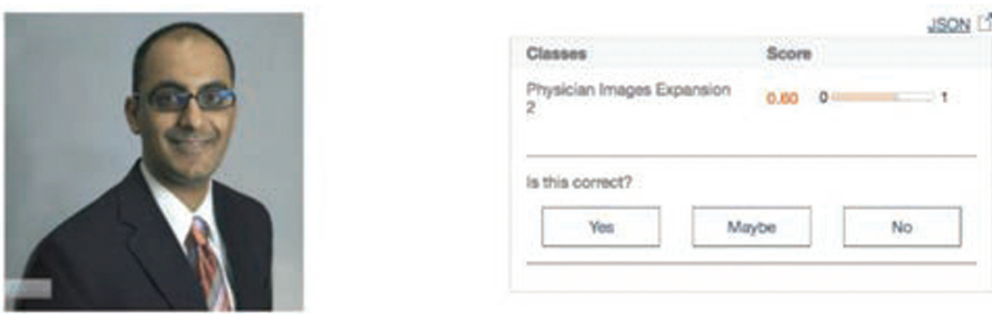

Figure 21 Image Profile Matching Score for Neil Sanghvi, MD.
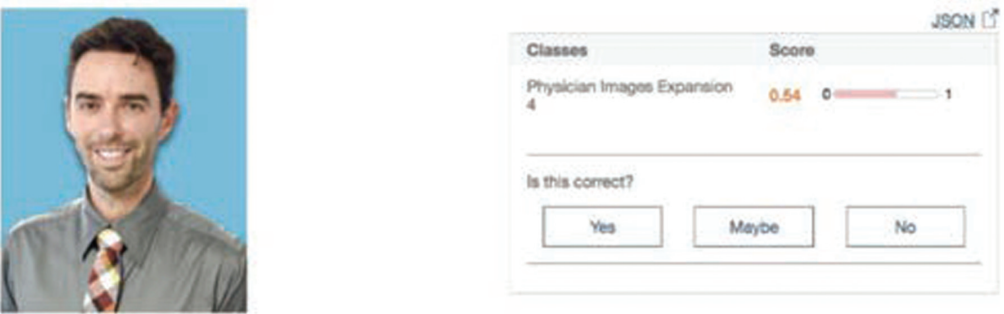

Figure 22 Image Profile Matching Score for Breck Thrash, MD.

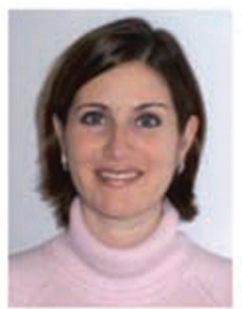

The score for this inage is not above the threshold of 0.5 based on the training data provided.

is this cornoct?

Yos

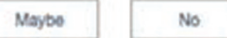

Figure 23 Image Profile Matching Score for Tamar Finan, MD. 
There were multiple images from the Aspirus database [38] and individual providers that were not recognized by IBM Watson visual recognition analytics [8], thereby yielding a biometric profile matching score below the threshold of 0.5 (examples of such being displayed in Figures 13 and 26). Some possible explanations of this experimental failure can be attributed towards image resolution discrepancies or a difference in image quality. It should be noted that all of the profile images provided on the HealthGrades website [29] were of significantly less quality than those pulled directly from the Aspirus database [38]. This resulted in IBM Watson analytics returning visual recognition match scores of an average of 0.57 . Differences in both image size along with resolution quality were the most influential variables in the scores returned. Images with a relatively higher resolution and size scored up to four tenths higher than those of poorer quality. The images sourced from the Sharecare and ZocDoc websites were found to be significantly improved in quality compared to the Healthgrades images.

Subsequent adjustments of image resolution and size modification for the Aspirus images and the HealthGrades photo profiles proved to be ineffective as it was found to have no effect on the resulting match scores. For instance, modifications to the HealthGrades image of Douglas P. Galuk, MD (as exhibited in Figure 16) for image quality enhancement yielded no change in the performance of IBM Watson analytics. The same original matching score of 0.60 was returned, despite altering the image size to 2592 by 3888 pixels to match the exact resolution and size of the corresponding Aspirus image. A resizing of successfully recognized images down to 25 by 33 pixels demonstrated that it was the minimum threshold pixel size for successful recognition by IBM Watson analytics (while validating images of that size, IBM Watson did not return a match score of above 0.5 ).

Other image recognition failures were seen due to images of significantly differing content, including elements such as the physican's age, attire, image quality, background and the picture style. A direct comparison of such images has been provided next to illustrate and explain the validation failure. In Figure 24, a side by side comparison can be seen of the "validator" and "validated" images for Shelbe Healy, MD. Both of these images were of satisfactory quality in terms of pixel size and image quality. However, IBM Watson failed to provide a positive recognition (as shown in Table 1), due to not only the different attire and appearance of the involved physician in each of the pictures, but also due to the age difference and background changes. 

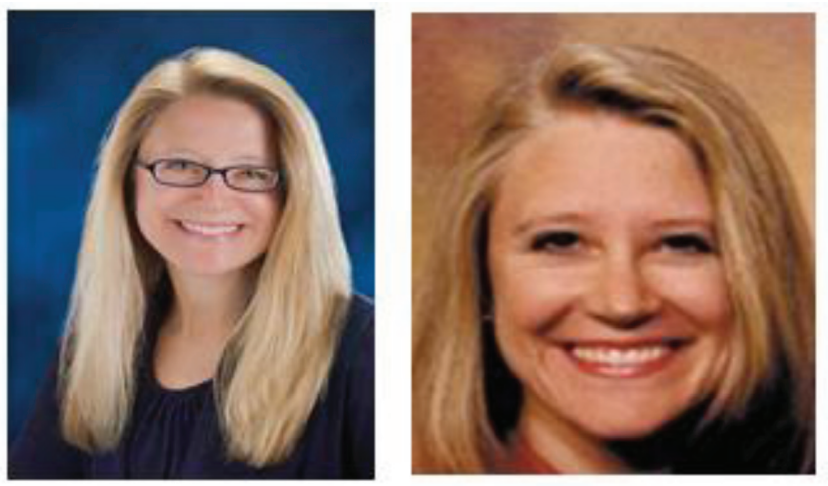

Figure 24 Shelbe Healy, MD: Aspirus (Left) and HealthGrades (Right).

The absence of glasses may also be of note as another reason for IBM Watson's non-match in this case. However, on the contrary, even with the case of Dr. William J. Montesano (as indicated by Figure 14) having a different pose, attire, and a slightly different appearance, IBM Watson analytics had still made a successful recognition. With the current image matching algorithms available in the visual recognition demo platform of IBM Watson, and the restriction on classifier file size, it is possible that IBM Watson is presently not capable of distinguishing major visual appearance differences such as the absence of glasses. It appears that Watson is capable of discerning significant differences in physician image backgrounds and even directional differences in which the physician is facing. A primary example of this is demonstrated by the image comparison of Dr. Carl Carlino in Figure 25.
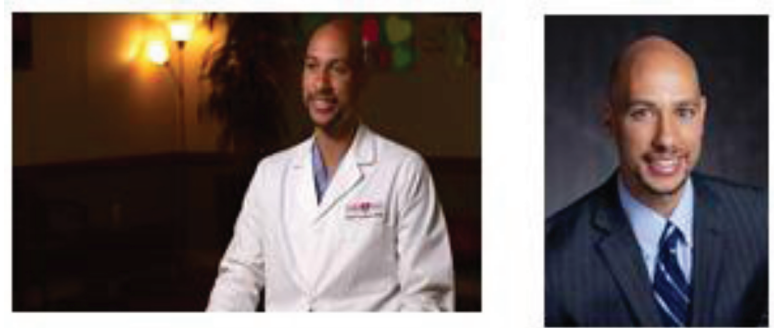

Figure 25 Carl Carlino, MD: Healthgrades (Left) and Austin Heart (Right).

Another example of Watson's image analysis capability lies in its successful analysis of Dr. Larry Crisco's images as shown in Figure 26. In the Sharepoint image, the physician is dressed in surgial robes while the healthcare 
network image has him in a suit. Watson was able to ignore this discrepancy and yield a successful match with a metric of 0.59 .
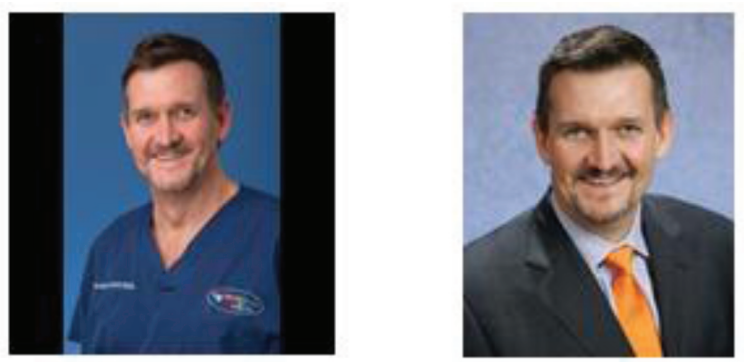

Figure 26 Larry Crisco, MD: Sharepoint (Left) and First Coast Heart (Right).

Watson provided another accurate result despite significant differences in the physican images for Dr. Alberto Manzor. As shown in Figure 27, the physician's coat, direction he is facing, background, and also, seemingly, his age all differ greatly. The other situation to note is that the ZocDoc image is entirely different in shape than the healthcare network image being circular in nature compared to what has been the standardized rectangular format.
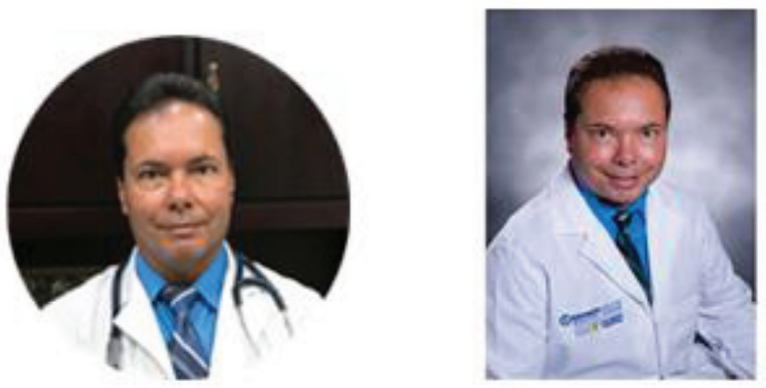

Figure 27 Alberto Manzor, MD: Zocdoc (Left) and Broward Health (Right).

A further demonstration of Watson's capabilities in discerning images beyond those possessing nearly identical characteristics comes from the image processing of Dr. Neil Sanghvi in Figure 28. The First Coast Heart image shows that Dr. Sanghvi is clearly younger and also in vastly different attire than the image provided by ZocDoc. An interesting image element is that Watson successfully identified these images even though in the ZocDoc image, 
Dr. Sanghvi is wearing a pair of glasses. This result is in stark contrast to the result from Dr. Shelbe Healy where the physician's age is different and in one of the images she was also wearing glasses, which lends it to be an almost exact comparison to this image set. Despite these differences, Watson still matched them and returned a score metric of 0.60 which was higher than some tested images that were nearly identical in image characteristics.
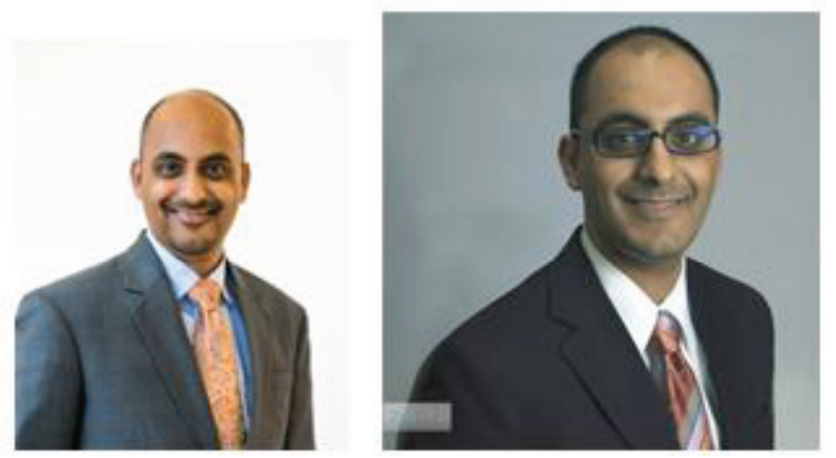

Figure 28 Neil Sanghvi, MD: First Coast Heart (Left) and Zocdoc (Right).

Figure 29 points out an instance of difference between the "validated" and "validator image quality (in terms of pixels). This image was pulled from the HealthGrades website and is inferior compared to the corresponding Aspirus profile, which is demonstrated in the left hand side picture's blurriness. IBM Watson analytics failed to make a match for both of these images due to the image quality differences, as evident here.
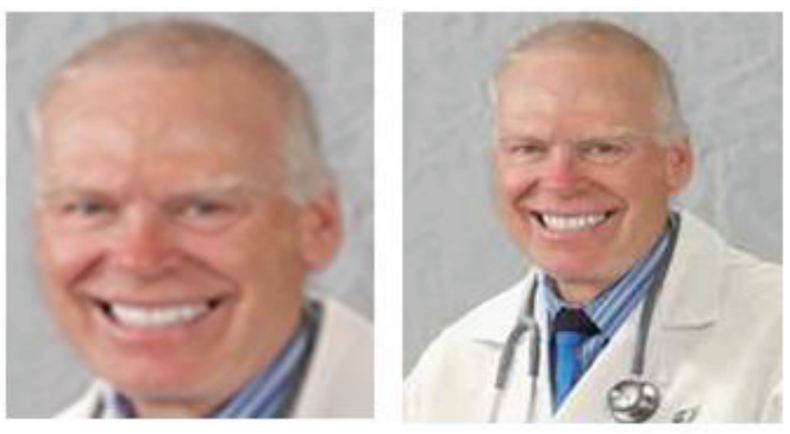

Figure 29 David Tange, MD: HealthGrades (Left) and Aspirus (Right).

As experimentation in image testing continued, it became readily apparent that image quality was a significant contributor to success or failure for visual 
recognition. Watson failed to recognize Dr. David Tange's images despite being nearly identical in nature, however it did recognize those of Dr. Breck Thrash as shown in Figure 30. The physician's images are identical save for the background including elements such as the tie pattern, facial expression, and shirt color. Image clarity is the primary difference between the images in Figure 30 and those in Figure 29. Dr. Thrash's images were superior in quality, permitting Watson to identify them successfully.

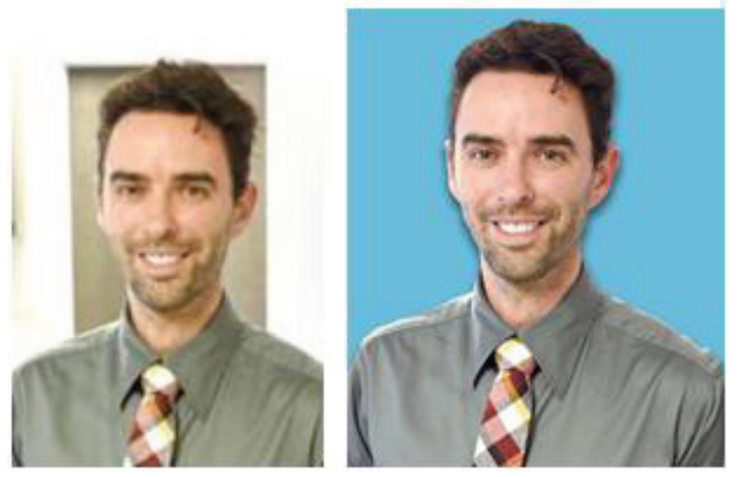

Figure 30 Breck Thrash, MD: Healthgrades (Left) and U.S. Dermatology (Right).

A further example of image quality being a paramount variable over characteristic differences was in the successful matching result of Dr. Christopher Maxwell in which Watson returned a score metric of 0.58 as shown in Figure 19. Dr. Maxwell's images were once again essentially identical in nature and significantly similar to the format of Dr. David Tange. The underlying difference once again came from the varying image qualities. The physician's images in Figure 29 present themselves in the same style of setting as those in Figure 31 with the Sharecare image possessing the emphasis of the image being on the physician's head while the image from Utah Gastroenterology focuses on not only the physican's head, but also his upper torso. Unlike Figure 29, Dr. Maxwell's images do not contain any blurry elements and the images are much sharper in terms of clarity.

Despite failing to provide a positive recognition for images in which image attributes varied too greatly in terms of content and image quality, IBM Watson analytics was able to return a high score of 0.60 for the image authentication for Richard Wessling, MD, as depicted in Figure 32. 

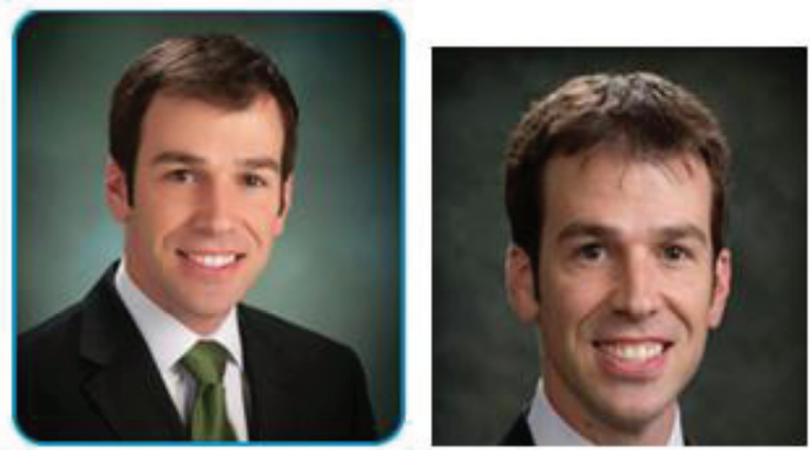

Figure 31 Christopher Maxwell, MD: Utah Gastroenterology (Left) Sharecare (Right).

While both of the "validator" and "validated" images possessed different qualities in terms of the age, clothing, pose and background, the image quality was quite high with a size of 1200 by 1500 pixels. Due to the quality of the validating Aspirus image, IBM Watson was able to match the facial features of the physician while scanning through the images with differing backgrounds, different depictions of age, and different clothing.
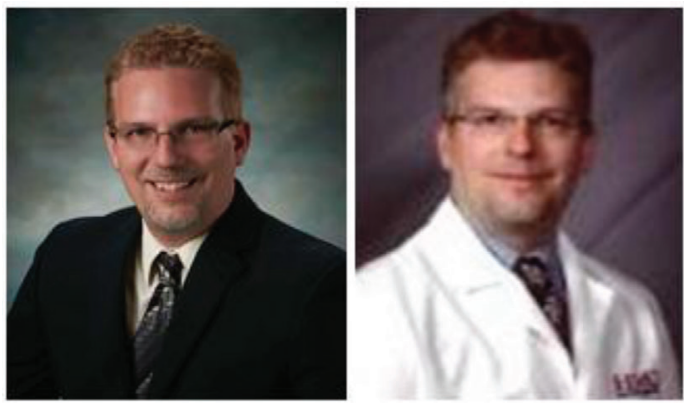

Figure 32 Richard Wessling, MD: Aspirus (left) and HealthGrades (Right).

Other physician images, which obtained a high IBM Watson score of 0.59 or greater (such as the images of Douglas Galuk, Rebecca Padilla, Patrick Allen and Thomas Smedberg), had validating Aspirus database images that had a high resolution (pixel count), with each measuring over 740 by 1000 pixels. Each of the corresponding validated reference website images from HealthGrades for each of the above physicians was either at or above the average 90 by 120 pixels. 
A curious anomaly in the experiment came from Watson's failure to successfully match the images of Dr. Tamar Finan. The images were identical except for the provider network image being in grayscale while the reference website image was in color. Due to Watson's analysis yielding a score of less than 0.50 the recognition was a failure on what appeared to be nothing more than a discrepancy in the images' coloration. This is shown in Figure 33.
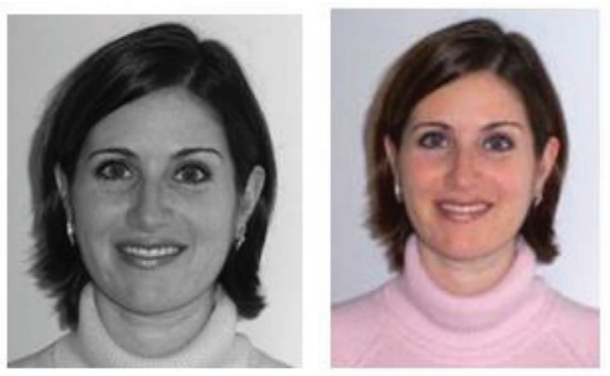

Figure 33 Tamar Finan, MD: Lahey Health (Left) and Healthgrades (Right).

From these image analyses, it is clear that higher image quality is needed to produce greater matching scores in visual recognition. Therefore, it is quite reasonable to state that for enabling success of the proposed biometric trust computational model, the published physician profile images need to comply with a set of image standards or guidelines. Ideally, for a successful authentication process, the visual profiles of providers need to be in accord amongst all online instances of their occurrences, which include "validator" and "validated" web sources. This means that the physicians (or providers) also need to play a part here by trusting and endorsing the OHI sites that post their profiles. Therefore, the proposed model will pave the potential path for development of trust at both the user and provider levels.

\section{Facial Recognition Based Biometrics as a Viable OHI Trustworthiness Indicator}

After conducting the model verification experiment with the collected physician images from some sample OHI websites [28, 29] against certified provider networks of images using IBM Watson's visual recognition analytics tool based biometric authentication [8], the successful visual profile matching rates, as obtained and reported in Table 1, indicate the prospects of the proposed biometrics based provider profile authentication model. 


\section{A. Chattopadhyay et al.}

Table 1 IBM Watson's Visual Recognition Analytics Based Biometric Research Findings: Image Wise Physician Profiles, Sources and The Corresponding Matching Scores

\begin{tabular}{|c|c|c|c|}
\hline \multirow[t]{5}{*}{ Physician } & \multicolumn{3}{|c|}{ IBM Watson Visual Recognition Data Analytics } \\
\hline & & Provider Class & \\
\hline & Selected OHI Reference & Image Profile & \\
\hline & Website (Validated Image & Source for & Match \\
\hline & Source) & Validation & Score \\
\hline Erik Anderson & HealthGrades.com [29] & Aspirus [38] & 0.58 \\
\hline Regis Chamberlain & HealthGrades.com [29] & Aspirus [38] & 0.53 \\
\hline Alberto Araya & HealthGrades.com [29] & Aspirus [38] & $<0.5$ \\
\hline William J. & ZocDoc.com [28] & Greater Rochester & 0.52 \\
\hline Montesano & & $\begin{array}{l}\text { Internal Medicine } \\
{[39]}\end{array}$ & \\
\hline Brian S. Smith & HealthGrades.com [29] & ABIM [30] & 0.59 \\
\hline Tyler Beckley & HealthGrades.com [29] & Aspirus [38] & 0.59 \\
\hline Kevin Ferreira & HealthGrades.com [29] & Aspirus [38] & 0.55 \\
\hline Douglas Galuk & HealthGrades.com [29] & Aspirus [38] & 0.60 \\
\hline David Tange & HealthGrades.com [29] & Aspirus [38] & $<0.5$ \\
\hline Rebecca Padilla & HealthGrades.com [29] & Aspirus [38] & 0.59 \\
\hline Shelbe Healy & HealthGrades.com [29] & Aspirus [38] & $<0.5$ \\
\hline Patrick Allen & HealthGrades.com [29] & Aspirus [38] & 0.59 \\
\hline Laurence Gordon & HealthGrades.com [29] & Aspirus [38] & 0.55 \\
\hline Matthew Clark & HealthGrades.com [29] & Aspirus [38] & 0.56 \\
\hline Daniel Priebe & HealthGrades.com [29] & Aspirus [38] & 0.59 \\
\hline Elizabeth Barr & HealthGrades.com [29] & Aspirus [38] & 0.58 \\
\hline Cody Nikolai & HealthGrades.com [29] & Aspirus [38] & 0.59 \\
\hline Bradley Boettcher & HealthGrades.com [29] & Aspirus [38] & 0.54 \\
\hline Thomas Smedberg & HealthGrades.com [29] & Aspirus [38] & 0.59 \\
\hline Richard Wessling & HealthGrades.com [29] & Aspirus [38] & 0.60 \\
\hline Adam Wolfe & HealthGrades.com [29] & $\begin{array}{l}\text { Metro Health } \\
\text { Hospital }\end{array}$ & $<0.5$ \\
\hline Ahmed Ahmed & HealthGrades.com [29] & Drahmedahmed.com & 0.60 \\
\hline Alberto Manzor & ZocDoc.com [28] & Broward Health & 0.62 \\
\hline Amanda Fontenot & HealthGrades.com [29] & $\begin{array}{l}\text { Ochsner Health } \\
\text { System }\end{array}$ & 0.56 \\
\hline Arnoldo Ghitis & HealthGrades.com [29] & $\begin{array}{l}\text { Heart and Health } \\
\text { Institute }\end{array}$ & 0.64 \\
\hline Andrea Natale & HealthGrades.com & $\begin{array}{l}\text { California Pacific } \\
\text { Medical Center }\end{array}$ & $<0.5$ \\
\hline Andrew Williams & HealthGrades.com [29] & $\begin{array}{l}\text { Centennial Primary } \\
\text { Care }\end{array}$ & 0.55 \\
\hline
\end{tabular}

(Continued) 
Table 1 Continued

\begin{tabular}{|c|c|c|c|}
\hline Physician & IBM Watson Visua & gnition Data Analyt & \\
\hline & & Provider Class & \\
\hline & Selected OHI Reference & Image Profile & \\
\hline & Website (Validated Image & Source for & Match \\
\hline & Source) & Validation & Score \\
\hline Basher & HealthGrades.com [29] & Florida Hospital & 0.50 \\
\hline Atiquzzaman & & Medical Group & \\
\hline Boyan Hadjiev & ZocDoc.com [28] & Drsneeze.com & 0.60 \\
\hline Breck Thrash & HealthGrades.com [29] & $\begin{array}{l}\text { U.S. Dermatology } \\
\text { Partners }\end{array}$ & 0.55 \\
\hline Carl Carlino & HealthGrades.com [29] & Austin Heart & 0.66 \\
\hline Christopher Davis & HealthGrades.com [29] & $\begin{array}{l}\text { Manatee } \\
\text { Cardiovascular } \\
\text { Wellness Institute }\end{array}$ & 0.55 \\
\hline Christopher & ShareCare.com & Utah & 0.58 \\
\hline Maxwell & & Gastroenterology & \\
\hline David Grech & HealthGrades.com [29] & First Coast Heart & $<0.5$ \\
\hline David Kessler & HealthGrades.com [29] & $\begin{array}{l}\text { Texas Cardiac } \\
\text { Arrhythmia }\end{array}$ & $<0.5$ \\
\hline Deborah Plante & HealthGrades.com [29] & Sutter Health & 0.61 \\
\hline Dinesh Pubbi & HealthGrades.com [29] & First Coast Heart & 0.57 \\
\hline Hans Sander & HealthGrades.com [29] & $\begin{array}{l}\text { U.S. Dermatology } \\
\text { Partners }\end{array}$ & $<0.5$ \\
\hline Dushvant Singh & HealthGrades.com [29] & $\begin{array}{l}\text { Gastrointestinal } \\
\text { Associates LLC }\end{array}$ & 0.55 \\
\hline $\begin{array}{l}\text { Efrem } \\
\text { Gebremedhin }\end{array}$ & HealthGrades.com [29] & $\begin{array}{l}\text { HCA Midwest } \\
\text { Physicians }\end{array}$ & $<0.5$ \\
\hline Erik Mondrow & HealthGrades.com [29] & $\begin{array}{l}\text { Flatiron Internal } \\
\text { Medicine }\end{array}$ & 0.55 \\
\hline Henry Cusnir & HealthGrades.com [29] & $\begin{array}{l}\text { Heart and Health } \\
\text { Institute }\end{array}$ & 0.55 \\
\hline Henry Gasioworski & HealthGrades.com [29] & $\begin{array}{l}\text { Greenwich } \\
\text { Dermatology }\end{array}$ & 0.56 \\
\hline Javed Yousaf & HealthGrades.com [29] & $\begin{array}{l}\text { Forest Healthcare } \\
\text { Associates }\end{array}$ & 0.55 \\
\hline Karen Weinstein & HealthGrades.com [29] & $\begin{array}{l}\text { Rush University } \\
\text { Medical Center }\end{array}$ & $<0.5$ \\
\hline Larry Crisco & ShareCare.com & First Coast Heart & 0.59 \\
\hline Maged Boutros & ZocDoc.com [28] & Prevention Clinics & 0.50 \\
\hline Michael Dahl & HealthGrades.com [29] & $\mathrm{HMCC}$ & 0.53 \\
\hline
\end{tabular}


Table 1 Continued

\begin{tabular}{|c|c|c|c|}
\hline Physician & IBM Watson Visua & gnition Data Analytics & \\
\hline & & Provider Class & \\
\hline & Selected OHI Reference & Image Profile & \\
\hline & Website (Validated Image & Source for & Match \\
\hline & Source) & Validation & Score \\
\hline Mohamed Shalaby & HealthGrades.com [29] & $\begin{array}{l}\text { Mohamed } \\
\text { Shalaby.com }\end{array}$ & $<0.5$ \\
\hline Muhamed Rifai & ZocDoc.com [28] & Alyrifai.com & 0.55 \\
\hline Neil Sanghvi & ZocDoc.com [28] & First Coast Heart & 0.60 \\
\hline Norman Risinger & HealthGrades.com [29] & Austin Heart & $<0.5$ \\
\hline Pamela Havlen & ShareCare.com & Skyline Primary & 0.51 \\
\hline Paolo Venegoni & HealthGrades.com [29] & $\begin{array}{l}\text { Cardiovascular } \\
\text { Specialists of Texas }\end{array}$ & 0.52 \\
\hline Paul Berlacher & HealthGrades.com [29] & Promedica & $<0.5$ \\
\hline Raji Venkat & HealthGrades.com [29] & Dignity Health & 0.62 \\
\hline Rohan Faria & HealthGrades.com [29] & Broward Health & $<0.5$ \\
\hline Robert Solomon & HealthGrades.com [29] & $\begin{array}{l}\text { Lewis Gale } \\
\text { Physicians }\end{array}$ & $<0.5$ \\
\hline Rupesh Parikh & HealthGrades.com [29] & $\begin{array}{l}\text { Comprehensive } \\
\text { Cancer Centers of } \\
\text { Nevada }\end{array}$ & 0.56 \\
\hline Saman Chubineh & HealthGrades.com [29] & Catholic Health & $<0.5$ \\
\hline Shazia Saif & HealthGrades.com [29] & $\begin{array}{l}\text { Certified } \\
\text { Dermatology of } \\
\text { New Jersey }\end{array}$ & $<0.5$ \\
\hline Stanley Wang & HealthGrades.com [29] & Austin Heart & 0.60 \\
\hline Steven Porter & HealthGrades.com [29] & $\begin{array}{l}\text { Ogden Regional } \\
\text { Medical Center }\end{array}$ & 0.51 \\
\hline Suhel Ahmed & HealthGrades.com [29] & $\begin{array}{l}\text { Advanced Med } \\
\text { Group }\end{array}$ & 0.66 \\
\hline Sunil Lal & ShareCare.com & $\begin{array}{l}\text { Augusta Health } \\
\text { Specialists }\end{array}$ & 0.56 \\
\hline Tamar Finan & HealthGrades.com [29] & Lahey Health & $<0.5$ \\
\hline Vincent Panella & ShareCare.com & $\begin{array}{l}\text { Gastroenterology } \\
\text { Group of Northern } \\
\text { New Jersey }\end{array}$ & 0.54 \\
\hline Zia Khan & HealthGrades.com & Dignity Health & 0.62 \\
\hline
\end{tabular}

Thus, the tabular results illustrate that visual recognition based biometrics can potentially act as a viable healthcare service provider-centric trustworthiness indicator for verifying $\mathrm{OHI}$ credibility and improving information assurance at the trustee or institutional level. An overall seventy-three percent (73\%) success rate for biometric matching was attained with successful visual 
recognitions for 50 out of 68 images, as seen in Table 2. The images obtained from HealthGrades [29], ZocDoc [28], and ShareCare.com were tested and divided into geographical regions, as shown in Table 3.

IBM Watson visual recognition analytics demonstrated the ability to correctly match physician profile pictures from different third party sources $[28,29]$ when validated against a corresponding provider network of images $[30,38,39]$. It also recognized and authenticated in tricky cases of verification, for instance when two photographs in comparison were not quite exactly alike, as seen in the given example of Figure 21, and in the corresponding experimental result shown in Table 1 . These observations suggest that the $\mathrm{OHI}$ trust formation can be enhanced at the user or trustor level (information assurance through verification) and the provider or trustee level (affiliation and endorsement by provider) by applying biometrics and implementing visual recognition driven authentication. Hence, the proposed biometric authentication based trust computational model will provide information assurance through validation of the physician profiles affiliated with the third party $\mathrm{OHI}$ that consumers are reading or seeking.

Table 2 Summary of IBM Watson's Visual Recognition Analytics Based Biometric Research Findings: Overall Image Source Wise Physician Profile Matching Instances

\begin{tabular}{|c|c|c|c|}
\hline \multicolumn{4}{|l|}{ Provider by State } \\
\hline Class Image Profile & Selected OHI Reference & Number & Number \\
\hline Source for & Website (Validated Image & & of Non- \\
\hline Validation & Source) & Matches & Matches \\
\hline Aspirus & HealthGrades.com [29] & 15 & 3 \\
\hline First Coast Heart & $\begin{array}{l}\text { HealthGrades.com and } \\
\text { Sharecare }\end{array}$ & 3 & 1 \\
\hline Austin Heart & HealthGrades.com & 2 & 1 \\
\hline Various Providers & $\begin{array}{l}\text { HealthGrades.com, } \\
\text { Sharecare, and Zocdoc }\end{array}$ & 30 & 13 \\
\hline
\end{tabular}

Table 3 Summary of IBM Watson's Visual Recognition Analytics Based Biometric Research Findings: Overall Image Source Wise Summarized By Geographical Region

\begin{tabular}{lll}
\hline $\begin{array}{l}\text { Provider by Geographic Region } \\
\text { Image Profile Source for } \\
\text { Validation }\end{array}$ & $\begin{array}{l}\text { Number of } \\
\text { Matches }\end{array}$ & $\begin{array}{l}\text { Number of } \\
\text { Non- } \\
\text { Matches }\end{array}$ \\
\hline Northeast & 8 & 3 \\
\hline Southeast & 11 & 3 \\
\hline Midwest & 17 & 7 \\
\hline Southwest & 5 & 4 \\
\hline West & 9 & 1 \\
\hline
\end{tabular}


Overall, the above IBM Watson visual recognition analytics based experiments enabled us to arrive at the following noteworthy points:

- Profile picture uniformity and consistency (in terms of image quality) across multiple $\mathrm{OHI}$ websites is required in order to obtain the most accurate visual recognition based biometric validation results.

- Images of a greater quality yield a higher visual recognition score than those of inferior quality, and this leads to a demand of higher quality profile images.

- Classifier images of higher quality from provider network sources enables stronger performance in biometric authentication and allows for greater variation and compromise in the quality of the reference OHI website profile images under validation.

- Adjusting and upgrading of image resolution plus size of inferior/poor quality images from reference OHI websites yields no improvement in IBM Watson's visual recognition based analytical performance.

\section{Mapping the Visual Recognition Analytic Tool's Potential Impact on Trust Antecedents}

The proposed visual recognition analytics tool could have a considerable impact on the process of trust between consumers and OHI websites by influencing trust antecedents. When discussing the possible effects of implementing the proposed visual recognition analytics tool, it is most salient to consider trust antecedents related to websites and online interaction with the organizations they represent. Therefore previous research in online trust antecedents was considered before determining how these antecedents may be affected by the proposed visual recognition analytics tool. The primary focus was on how these antecedents related to initial trust in a website, which is only the beginning of the multi-stage process of trust [10].

Once all specific, relevant trust antecedents (as seen in Section 2) were considered, it was determined which of these potential trust antecedents could be affected by the proposed visual recognition analytics tool. The result is Figure 34, which represents the process of how a consumer may grow to trust a third party OHI website when the visual recognition analytics tool is involved. Note that this does not represent the entire model of trust; instead this represents the process to gain initial trust from the consumer as a first step in a multi-staged trust process [10]. The process begins with the healthcare providers and third party $\mathrm{OHI}$ websites coming together to ensure compliance 


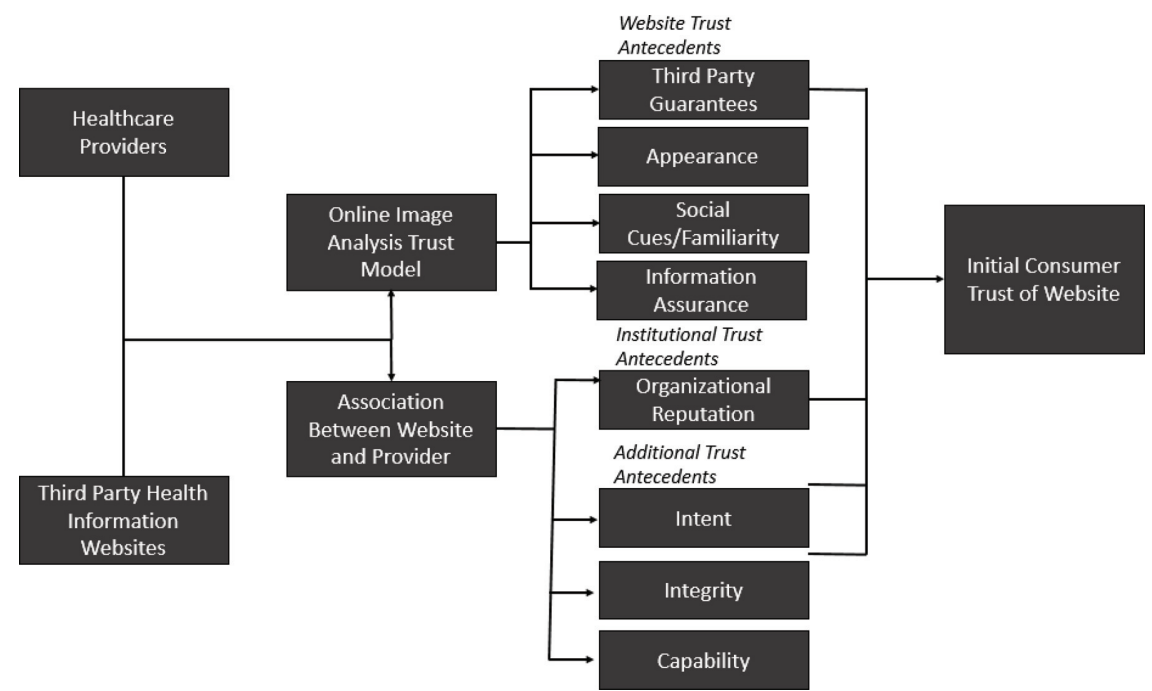

Figure 34 Block Diagram Mapping the Impact of the Proposed Visual Recognition Model on the Process of Trust.

with picture quality standards to make the image comparison possible (left side of Figure 34.). This results in implementation of the image analysis and also forms an association between the websites and the providers. Both of these results have an impact on the trust antecedents listed in the diagram.

Third party guarantees were found to be an antecedent of trust by consumers in the context of websites [36]. The online image analysis proposed here would act as a guarantee by a third party, ensuring that there is matching between the providers and the $\mathrm{OHI}$ websites.

"Appearance" as discussed in Section 2 can involve the desire to see a human face attached to the website the individual is dealing with [18]. The necessary addition of high quality facial images that would be coupled with the use of the proposed visual recognition model would benefit this trust antecedent for this reason.

Social Cues and Familiarity are related to the notion of the user (or consumer) interacting through a personalized, social touch when using a website, and past experiences with known parties, respectively. These are both affected in the same way by seeing a picture of a familar doctor (who a consumer may have past experiences with), which increases the chances of a positive impact during user interaction with users [36].

In addition to enhancing trust from a website perspective, the online image analysis could also affect trust in the institution being represented by 
the website. Institutional trust antecedents include organizational reputation and offline presence. The implementation process of the visual recognition analytics tool would enhance the perceived reputation of the organization by associating it directly with the providers themselves.

Intent, Integrity and Capability are additional parameters of trust that we have included as potential trust antecedents [41]. Intent represents the "willingness" of the trustee to perform actions as the trustor expects. In the case of our model, the action the trustee (the third party OHI website) would be trusted to perform is to accurately represent the individual that it claims to represent. Integrity represents consistently meeting the expectations of different trustees. The online image analysis itself enhances this aspect of trust by giving a tool to detect when a page is not representing the individual in question, and therefore not meeting the expectation of the trustor. Capability, the resources needed to meet expectations of users could be increased by the website's relationship with providers; they are more able to accurately represent the providers in question (the users' expectations) with this model in place.

Through these antecedents, the image analysis that we propose would impact the initial trust consumers have in $\mathrm{OHI}$ websites (far right side of Figure 34).

\section{Conclusion: Overall Summary and The Future}

The main contribution of this paper is a novel biometric authentication based hybrid trust-computing model that innovates $\mathrm{OHI}$ trust related research by exploiting a unique provider-centric approach and verifies trust constructs at the institutional level. This first of its kind provider-profile based biometric authentication model can be used to expand the trust of online healthcare consumers on OHI content (involving third party websites). In a way, this innovative model can also help to extend the trust of healthcare providers on the OHI websites (involving third parties) by indirectly advocating for collaboration between healthcare providers and the third party $\mathrm{OHI}$ websites. The presented work represents a unique application of computer vision based visual recognition biometrics to the field of information assurance based trust computation in OHI.

The real-life implementation process of the proposed model would become much easier and get a boost to serve its intended purpose, if the providers would actually endorse the $\mathrm{OHI}$ content of the third party websites, and share their authentic institutional profiles. However, since this proposed model 
uses physician image profiles to effect visual recognition driven biometric validation, its successful implementation depends on the existence of online visual profiles for physicians as well as on the quality plus resolution of the images. The conducted research experiments with IBM Watson's visual recognition based analytics [8] reveal that the provider image profiles, as used with OHI, need to conform to certain minimal standards of resolution and quality. These observations along with the experimental dataset of the provider images would act as valuable inputs and a primary research knowledge base for future work in this area.

The research conducted in this paper seeks to explore the trustworthiness of $\mathrm{OHI}$ through verification of provider profiles via visual recognition based cross-validation. In the process, it investigates OHI elements and attributes that are connected to the perception of trust building through biometric authentication. One of the limitations that came up in the scope of our research was the inconsistency in the use of actual provider image profiles in the $\mathrm{OHI}$ domain websites. Another challenge faced during the experiments was the lack of quality provider images, given that many of the collected provider images from OHI websites were of low resolution and poor image quality. Thus, this research indirectly lobbies for publishing more visual provider profiles of better quality in the OHI domain. Thus, this project sets up the foundation for further research on hybrid-trust driven policy-making in online healthcare consumerism [40].

The next plan of action in this research project is the creation of a prototype software application that shall represent a functional tool for automation of the biometric authentication process presented in this paper. Future research and development work shall also involve design and development of an actual OHI trust metric that generates more meaningful and holistic trust scores for online health consumers. Other potential future work includes deployment of the presented $\mathrm{OHI}$ trust-computing model within the actual healthcare community, including online healthcare consumers and providers in an effort to collect feedback data from the $\mathrm{OHI}$ users and providers as part of the research study as to whether the proposed model can improve trust and counter cyberchondria. Lastly, the use of pattern recognition techniques for verifying OHI website logo affiliations could be a possible step for another potential hybrid trustcomputing approach in this sector. Overall, given the prolific use of OHI websites by today's consumers, it is imperative that a resource for determining the credibility, authenticity and trustworthiness of OHI be developed. The prospective model presented here would represent the first technical hybrid 
model exploiting both "soft trust" and "hard trust" markers to validate and verify $\mathrm{OHI}$ websites in order to determine their credibility.

\section{References}

[1] Fox, S., "Mobile Health 2010," Pew Internet and American Life Project.

[2] Barbara, A. M., Dobbins, M., Haynes, R. B., Iorio, A., Lavis, J. N., Raina, P., and Levinson. A. J. (2016). "The McMaster Optimal Aging Portal: Usability Evaluation of a Unique Evidence-Based Health Information Website," JMIR Human Factors 3, no. 1.

[3] Brainin, E., and Neter, E. (2014). "Inside Technology: Opening the Black Box of Health-Website Configuration and Content Management," Future Internet 6, no. 4, 773-799.

[4] Turkiewicz, K. L. (2012). "Cyberchondria scale construction: The Cyberchondria Assessment Measure (CYCAM), " Paper presented at the Central States Communication Association Conference, Cleveland, $\mathrm{OH}$. Health Communication Interest Group.

[5] White, R. W., and Horvitz, E. (2009). "Cyberchondria: Studies of the escalation of medical concerns in web search," ACM Transactions on Information Systems, 27, 1-37.

[6] Muse, K., Mcmanus, F., Leung, C., Meghreblian, B., and Williams. J. M. G. (2009). "Cyberchondriasis: Fact or fiction? A preliminary examination of the relationship between health anxiety and searching for health information on the Internet," Journal of Anxiety Disorders 26, no. 1 (2012): 189-96.

[7] Starcevic, V., and Aboujaoude, E. (2015). "Cyberchondria, Cyberbullying, Cybersuicide, Cybersex: "New" Psychopathologies for the 21st Century?" World Psychiatry, 14(1):97-100. doi: 10.1002/wps.20195.

[8] "IBM Watson Visual Recognition Demo," IBM. N.p., 2017. Web. 5 Jan. 2017. Print. https://visual-recognition-demo.mybluemix.net/. Available at: https://www.ibm.com/watson/developercloud/doc/visualrecognition/index.html

[9] Alpaslan, A. H. (2016). "Cyberchondria and adolescent," Social Psychiatry $1,2$.

[10] Sillence, E., Briggs, P., and Harris, P. R. (2009). "Healthy persuasion: web sites that you can trust," Persuasive Technology and Digital Behaviour Intervention Symposium.

[11] Khosrowjerdi, M. (2016). "A review of theory-driven models of trust in the online health context," IFLA journal 42, no. 3, 189-206. 
[12] Singal, H., and Kohli, S. (2016). "Trust Necessitated through Metrics: Estimating the Trustworthiness of Websites," Procedia Computer Science 85, 133-140.

[13] Sänger, J., and Pernul, G. (2016). "TRIVIA: visualizing reputation profiles to detect malicious sellers in electronic marketplaces," Journal of Trust Management 3, no. 1, 5.

[14] Kostagiolas, P., Korfiatis, N., Kourouthanasis, P., and Alexias, G. (2014). "Work-related factors influencing doctors search behaviors and trust toward medical information resources," International Journal of Information Management 34, no. 2, 80-88.

[15] Yap, M. N., Kamalrudin, M., Bakar, A. Z. A., and Sidek, S. (2016). "Verification on the Trustworthiness of Information: A Study," Journal of Theoretical and Applied Information Technology 92, no. 1, 72.

[16] Giasemidis, G., Singleton, C., Agrafiotis, I., RC Nurse, J., Pilgrim, A., Chris Willis, and Greetham, D. V. (2016). "Determining the veracity of rumours on Twitter," International Conference on Social Informatics, pp. 185-205. Springer International Publishing.

[17] Pauer, F., Göbel, J., Storf, H., Litzkendorf, S. Babac, A., Frank, M., Lührs, V. et al. (2016) "Adopting Quality Criteria for Websites Providing Medical Information About Rare Diseases," Interactive Journal of Medical Research 5, no. 3.

[18] Kim, Y. (2014). "Trust in health information websites: A systematic literature review on the antecedents of trust," Health informatics journal, 1460458214559432.

[19] Lazard, A. J., and Mackert, M. S. (2015). "E-health first impressions and visual evaluations: key design principles for attention and appeal," Communication Design Quarterly Review 3, no. 4, 25-34.

[20] Johnson, F., Rowley, J., and Sbaffi, L. (2015). "Modelling trust formation in health information contexts," Journal of Information Science, 0165551515577914.

[21] Sillence, E., and Briggs, P. (2015). "Trust and Engagement in Online Health A Timeline Approach," Handb PsycholCommun Technol 33, 46987.

[22] Bakke, A. (2016). "Ethos in E-Health: From Informational to Interactive Websites," Establishing and Evaluating Digital Ethos and Online Credibility, 85.

[23] Vega, L. C., DeHart, T., and Montague, E. (2011). "Trust between patients and health websites: a review of the literature and derived outcomes from empirical studies," Health and technology 1, no. 2-4, 71-80. 
[24] Sillence, E., and Briggs, P. (2007). "The Evolution of Trust in a Design Contex," Design and semantics of form and movement 30,

[25] Rafe, V., and Monfaredzadeh, M. (2012). "A qualitative framework to assess hospital/medical websites," Journal of Medical Systems 36, no. 5, 2927-2939.

[26] Corritore, C. L. Wiedenbeck, S., Kracher, B., and Marble, R. P., (2012). "Online trust and health information websites," International Journal of Technology and Human Interaction (IJTHI) 8, no. 4, 92-115.

[27] Chattopadhyay, A. (2016). "Developing an Innovative Framework for Design and Analysis of Privacy Enhancing Video Surveillance." $\mathrm{PhD}$ diss., University of Colorado Colorado Springs. Kraemer Family Library.

[28] "Zocdoc," Zocdoc. N.p., 2017. Web. 10 Jan. 2017. Available at: https://www.zocdoc.com/

[29] "Healthgrades Find A Doctor |Doctor Reviews |Hospital Ratings," Healthgrades. N.p., 2017. Web. 9 Jan. 2017. Available at: https://www.healthgrades.com/

[30] "Home |ABIM.Org," Abim.org. N.p., 2017. Web. 9 Jan. 2017. Available at: http://www.abim.org/

[31] Kuo, M. (2011). "Opportunities and challenges of cloud computing to improve health care services," Journal of medical Internet research 13, no. 3 , e67.

[32] Athanasiou, G., and Lymberopoulos, D. (2016). "A comprehensive Reputation mechanism for ubiquitous healthcare environment exploiting cloud model," Engineering in Medicine and Biology Society (EMBC), 2016 IEEE 38th Annual International Conference, pp. 5981-5984.

[33] Martínez-Sarriegui, I., García-García, F., García-Sáez, G., Hernando, M. E., and Luck, M. (2012). "TRHIOS: Trust and reputation in hierarchical and quality-oriented societies," Information Systems and Technologies (CISTI), 2012 7th Iberian Conference, pp. 1-4. IEEE.

[34] Msanjila, S. S., and Afsarmanesh, H. (2009). "On hard and soft models to analyze trust life cycle for mediating collaboration," Working Conference on Virtual Enterprises, pp. 381-392. Springer Berlin Heidelberg.

[35] Lin, C., and Varadharajan, V., (2007). "Ahybrid trust model for enhancing security in distributed systems," Availability, Reliability and Security, (2007). ARES 2007. The Second International Conference on, pp. 35-42, IEEE. 
[36] Beldad, A, De Jong, M., and Steehouder, M. (2010). "How shall I trust the faceless and the intangible? A literature review on the antecedents of online trust," Computers in Human Behavior 26, no. 5, 857-869.

[37] Singal, H., and Kohli, S. (2016). "Mitigating Information Trust: Taking the Edge off Health Websites," International Journal of Technoethics (IJT) 7, no. 1, 16-33.

[38] "Home |Aspirus Main,"Aspirus.org. N.p., 2017. Web. 18 Mar. 2017. Available at: http://www.aspirus.org

[39] "Greater Rochester Internal Medicine," Grinternalmedicine.com. N.p., 2017. Web. 18 Mar. 2017. Available at: http://www.grinternal medicine.com

[40] Chattopadhyay, A., and Turkiewicz, K. (2017). "Future Directions In Online Healthcare Consumerism Policy Making: Exploring Trust Attributes Of Online Healthcare Information |IEEE Internet Initiative," Internetinitiative.ieee.org. N.p., 2017. Web. 24.

[41] Salah, H., Eltoweissy, M. (2017). "On the personalization of trust management." IEEE Symposium on Security and Privacy Workshops.

[42] Wang, H. 2017. "How trust have been researched in HCI."

[43] "Adam T. Wolfe, DO," Metrohealth.net. N.p., Web. 20 Sep. 2017. Available at: https://metrohealth.net/find-a-doc/doctor/adamtroywolfe/

[44] "Cardiologists Webster, TX," Drahmed.com. N.p., Web. 20 Sep. 2017. Available at: https://www.drahmedahmed.com/

[45] "Alberto Manzor, MD,” Browardhealth.org. N.p., Web. 20 Sep. 2017. Available at: https://www.browardhealth.org/doctor/profile/AlbertoManzor/629146

[46] "Amanda Fontenot" Ochsner.org. N.p., 2017. Web. 20 Sep. 2017. Available at: https://www.ochsner.org/doctors/amanda-fontenot

[47] "Primary Care and Cardiology," Heartandhealthinst.com. N.p., Web. 20 Sep. 2017. Available at: http://heartandhealthinst.com

[48] "Andrea Natale, MD, FACC," Cpmc.org. N.p., Web. 20 Sep. 2017. Available at: http://www.cpmc.org/dr-andrea-natale.html

[49] “Andrew J Williams MD," Centennialprimarycare.secure.com. N.p., Web. 20 Sep. 2017. Availabel at: https://centennialprimarycare.secure. ehc.com/physicians/profile/Dr-Andrew-J-Williams-MD

[50] "Dr. Basher Atiquzzaman," Fhmedicalgroup.com. N.p., 2017 Web. 20 Sep. 2017. Available at: https://www.fhmedicalgroup.com/providers/drbasher-atiquzzaman 
[51] "Dr. Sneeze |Boyan Hadjiev, MD 20 E40th. Ste. 1204, New York NY, 10016.” Drsneeze.com. N.p., Web. 20 Sep. 2017. Available at: http://drsneeze.com/

[52] “U.S. Dermatology Partners," Usdermatologypartners.com. N.p., Web. 20 Sep. 2017. Available at: https://www.usdermatologypartners.com

[53] "Cardiology in Austin, TX," Austinheart.com. N.p., Web. 20 Sep. 2017. Available at: https://austinheart.com

[54] "Dr.-Christopher-Davis-221x300.jpg," Manateecardio.com. N.p., Web. 20 Sep. 2017. Available at: http://manateecardio.com/wp-content/ uploads/2014/12/Dr.-Christopher-Davis-221x300.jpg

[55] "Christopher I. Maxwell, MD," Utahgastro.com. N.p., Web. 20 Sep. 2017. Available at: http://www.utahgastro.com/christopher-i-maxwellmd

[56] "Home," Firstcoastheart.com. N.p., Web. 20 Sep. 2017. Available at: http://www.firstcoastheart.com

[57] “Texas Cardiac Arrhythmia: David J Kessler, MD," Tcaheart.com. N.p., Web. 20 Sep. 2017. Available at: https://tcaheart.com/physicians/davidj-kessler-md

[58] "Dr. Deborah K. Plante M.D., Endocrinologist in Roseville, CA," Sutterhealth.org. N.p., Web. 20 Sep. 2017. Available at: https://www.sutterhealth.org/find-doctor/dr-deborah-k-plante.

[59] "Our Providers," Kc-gi.com. N.p., Web. 20 Sep. 2017. Available at: http://www.kc-gi.com/physicians/our-physicians

[60] "Kansas City Network of Doctors," Mymidwestphysician.com. N.p., Web. 20 Sep. 2017. Available at: https://mymidwestphysician.com

[61] "Erik Mondrow, M.D.," Flatironinternalmed.com. N.p., Web. 20 Sep. 2017. Available at: http://www.flatironinternalmed.com/erik-mondrow$\mathrm{m}-\mathrm{d} /$

[62] "Greenwich Dermatology," Greenwichdermatology.com. N.p., Web. 20 Sep. 2017. Available at: http://www.greenwichdermatology.com/aboutus/

[63] "Forest Healthcare Associates Javed Yousaf, M.D.," Foresthealthcare.com. N.p., Web. 20 Sep. 2017. Available at: http://www.foresthealth care.com/our-doctors/javed-yousaf-m-d/

[64] "Karen B. Weinstein, MD," Doctors.rush.edu. N.p., Web. 20 Sep. 2017. Available at: https://doctors.rush.edu/details/1496/karenweinstein-internal_medicine_pcp-oak_park

[65] "Dr. Maged T. Boutros, MD," Preventionclinics.com. N.p., Web. 20 Sep. 2017. Available at: http://preventionclinics.com/shw_team/dr-boutros/ 
[66] “Cardiovascular Doctor," Drshalaby.com. N.p., Web. 20 Sep. 2017. https://drshalaby.com/.

[67] "Muhamad Aly Rifai, MD,” Alyrifai.com. N.p., Web. 20 Sep. 2017. Available at: http://www.alyrifai.com/

[68] "Pamela Havlen MD," Skylineprimary.secure.ehc.com. N.p., Web. 20 Sep. 2017. Available at: https://skylineprimary.secure.ehc.com/ physicians/profile/Pamela-Havlen-MD

[69] "Paolo V Venegoni, MD, FACC," Cstheart.com. N.p., Web. 20 Sep. 2017. Available at: https://cstheart.com/physicians/profile/Dr-Paolo-VVenegoni-MD

[70] "Paul D Berlacher MD, FACC," Promedica.org. N.p., Web. 20 Sep. 2017. Available at: https://www.promedica.org/provider/paul-dberlacher-md-facc-cardiology

[71] "Dignity Health," Dignityhealth.org. N.p., Web. 20 Sep. 2017. Available at: https://www.dignityhealth.org

[72] “Dr. Robert C. Solomon, MD, FACP," Lgphysicians.com. N.p., Web. 20 Sep. 2017. Available at: http://lgphysicians.com/physicians/profile/ Robert-C-Solomon-MD-FACP

[73] "Rupesh J. Parikh, MD," Ccnevada.com. N.p., Web. 20 Sep. 2017. Available at: https://www.cccnevada.com/doctor/rupesh-j-parikh-md/

[74] "Contact Dr. Sman B. Chubineh," Chsbuffalo.org. N.p., Web. 20 Sep. 2017. http://www.chsbuffalo.org/Physicians/SamanBChubineh

[75] "Our Providers," Njdermdoc.com. N.p., Web. 20 Sep. 2017. Available at: http://njdermdoc.com/our-providers/

[76] "Steven A Porter MD," Ogdenregional.secure.ehc.com. N.p., Web. 20 Sep. 2017. Available at: https://ogdenregional.secure.ehc.com/ physicians/profile/Steven-A-Porter-MD

[77] "Dr. Suhel Ahmed, MD," Advancemedgroup.com. N.p., Web. 20 Sep. 2017. Available at: http://advancemedgroup.com/providers/suhelahmed-md/

[78] "Sunil K Lal MD," Augustahealthspecialists.com. N.p., Web. 20 Sep. 2017. Available at: https://augustahealthspecialists.com/physicians/ profile/Sunil-K-Lal-MD

[79] "Tamar M. Finan, MD," Laheyhealth.org. N.p., Web. 20 Sep. 2017. Available at: http://www.laheyhealth.org/findadoctor/physician?PID= Tamar-Finan-8

[80] "Dr. Vincent Panella," Englewoodgi.org. N.p., Web. 20 Sep. 2017. Available at: http://www.englewoodgi.com/vincent-s-panella.html 
[81] "Sharecare: Get Expert Health Advice, Find a Doctor \& Manage Your Health," Sharecare.com. N.p., Web. 20 Sep. 2017. Available at: https://www.sharecare.com/

[82] "OHI Hybrid Trust Computing Physician Profile Images DataSet, “ Github.com. N.p., Web. 27 Mar. 2018. Available at: https://github.com/ azzandra/TrustComputing

\section{Biographies}

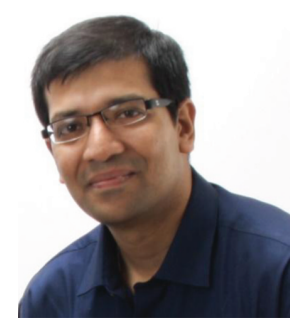

Ankur Chattopadhyay is an Assistant Professor in the Information and Computing Sciences (ICS) department at the University of Wisconsin, Green Bay. He has a Ph.D. in computer science from the University of Colorado. His research interests include information assurance and cybersecurity, privacyenhancing computer vision and pattern recognition, image processing \& analysis, and computer science plus security education. He has published and presented in international conferences like IEEE Security \& Privacy, ACM SIGCSE, IEEE CVPR and IEEE FIE. Chattopadhyay has more than 16+ years of experience in both academics and industry. As an academician, his passion is innovating computer science plus cybersecurity education, conducting research and applying his research to benefit the society. His industry profile includes multiple roles such as IT analyst, software engineer and embedded systems engineer, having worked with Tata Consultancy Services for several years. 


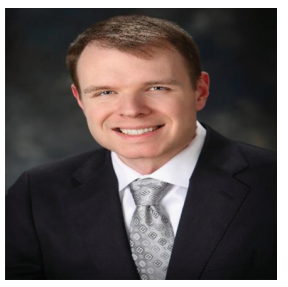

Michael J. Schulz is an associate programming analyst at Express Scripts. He received his Bachelor's degree in Computer Science from the University of Wisconsin Green Bay where his coursework placed an emphasis on big data and data science. Michael continues to explore his passions in data science in the healthcare industry where he seeks to leverage data through machine learning in order to obtain the best outcomes for patients. He is currently pursuing his Master's degree in Data Science in the University of Wisconsin.

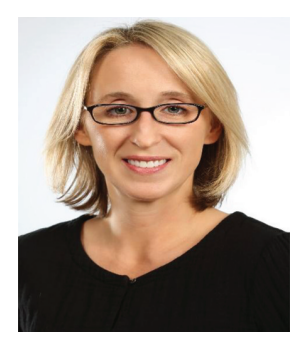

Katie L. Turkiewicz is an Assistant Professor in the Information and Computer Science Department at the University of Wisconsin Green Bay. She received her MA and Ph.D. from the University of Wisconsin Milwaukee where her research focus included online health information seeking practices. Dr. Turkiewicz continues to explore the impact of counterproductive online health information seeking on the provider-patient relationship in addition to the impact of new technology on health. 
46 A. Chattopadhyay et al.

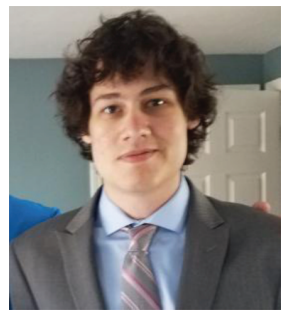

Eli Hughes spent three years at the University of Wisconsin Green Bay studying Health and Organizational communication before graduating with a Bachelor's degree emphasizing both of those areas in 2017. Eli is particularly interested in areas of study focused on Cyberchondria and Health Anxiety. He has recently started his career in the transportation industry and remains highly interested in research, lifelong learning, and the study of communication 